\title{
Respiratory syncytial virus entry and how to block it
}

Michael B. Battles ${ }^{1}$ and Jason S. McLellan (iD ${ }^{2 *}$

Abstract | Respiratory syncytial virus (RSV) is a leading cause of lower respiratory tract disease in young children and elderly people. Although the virus was isolated in 1955, an effective RSV vaccine has not been developed, and the only licensed intervention is passive immunoprophylaxis of high-risk infants with a humanized monoclonal antibody. During the past 5 years, however, there has been substantial progress in our understanding of the structure and function of the RSV glycoproteins and their interactions with host cell factors that mediate entry. This period has coincided with renewed interest in developing effective interventions, including the isolation of potent monoclonal antibodies and small molecules and the design of novel vaccine candidates. In this Review, we summarize the recent findings that have begun to elucidate RSV entry mechanisms, describe progress on the development of new interventions and conclude with a perspective on gaps in our knowledge that require further investigation.
Nasopharynx

The upper part of the pharynx that connects with the nasal cavity.

Bronchioles

Small tubes in the lung through which air is delivered to the alveoli.

Alveoli

Small air sacs in the lung that provide rapid gas exchange with blood.

Bronchiolitis

Inflammation of the bronchioles that reduces air passage.

Formalin

An aqueous solution of

formaldehyde.

'Department of Biochemistry and Cell Biology, Geisel School of Medicine at Dartmouth, Hanover, NH, USA.

${ }^{2}$ Department of Molecular Biosciences, The University of Texas at Austin, Austin,

TX, USA.

*e-mail:jmclellan@

austin.utexas.edu

https://doi.org/10.1038/

s41579-019-0149-x
Respiratory syncytial virus (RSV) was first isolated in 1955 from chimpanzees suffering from respiratory illness at the Walter Reed Army Institute of Research in the United States ${ }^{1}$. In the following years, the virus was also isolated from infants with severe lower respiratory illness ${ }^{2,3}$. Since then, RSV has been demonstrated to be a ubiquitous pathogen that infects nearly all children by 2 years of age, with one-half having experienced two infections during that time ${ }^{4}$. Globally, RSV is responsible for $\sim 60,000$ in-hospital deaths annually in children younger than 5 years of age ${ }^{5}$, and in the United States, RSV has a disease burden similar to that of nonpandemic influenza A for elderly and high-risk adults $^{6}$. Recognition of the substantial disease burden attributable to RSV has ignited interest in the development of effective interventions and has led to substantial investments by pharmaceutical companies and philanthropic organizations.

RSV is a filamentous enveloped, negative-sense, single-stranded RNA virus that belongs to the Orthopneumovirus genus of the Pneumoviridae family in the order Mononegavirales. This family also contains human metapneumovirus (hMPV), which belongs to the Metapneumovirus genus and, like RSV, is a major pathogen in children ${ }^{7}$. The symptoms of RSV and hMPV infection are indistinguishable ${ }^{8}$, and both are generally transmitted through close contact ${ }^{9,10}$, although they can be spread in aerosolized droplets ${ }^{11}$. After a short period of replication in the epithelial lining of the nasopharynx and upper respiratory tract, an RSV infection may spread to the small bronchioles or alveoli of the lower respiratory $\operatorname{tract}^{12}$. Host immune responses to RSV infection increase mucus production and inflammation, leading to a narrowing of the airway that results in bronchiolitis in young children and acute respiratory illness in older adults or those with underlying chronic conditions ${ }^{13}$. During a series of clinical trials in the 1960 s, aberrant immune responses to natural infection after immunization with a formalin-inactivated whole-virus RSV vaccine were shown to cause vaccine-enhanced disease in infants ${ }^{14-17}$. This disease was characterized in part by pulmonary neutrophil infiltration ${ }^{18}$ and immune complex deposition in small airways ${ }^{19}$. As a result of those trials, RSV vaccine development has progressed cautiously, particularly in RSV-naive infants.

Currently, there are no licensed vaccines for RSV, but in the past 5-10 years, there have been tremendous efforts, with over 30 different vaccine candidates in clinical or preclinical development. There are multiple vaccine target populations - pregnant women, elderly individuals and RSV-naive infants - and each will likely benefit from a specific vaccine modality or regimen. The legacy of vaccine-enhanced disease has, in part, led to the development of alternative interventions, such as those using monoclonal antibodies and small molecules. This set of alternatives includes the FDA-approved monoclonal-antibody therapy licensed under the brand name Synagis, also known as palivizumab. However, its use is restricted to passive immunoprophylaxis of high-risk infants owing to its cost and modest efficacy ${ }^{20}$, and more potently neutralizing antibodies with longer half-lives are in development. Like antibodies, small-molecule fusion inhibitors block RSV entry, and they avoid concerns related to enhanced disease upon natural infection. 
Neutrophil

Most abundant type of white blood cell.

Immune complex

An antibody bound to its

antigen.

Passive immunoprophylaxis The administration of an exogenously produced antibody given before infection occurs.

Apoptosis

Programmed cell death.

Glycoproteins

Proteins to which

carbohydrates are covalently attached.
In this Review, we briefly describe the structure of the RSV virion and its infectious cycle. We focus on the recent progress that has been made in our understanding of the entry of RSV into host cells and discuss remaining unanswered questions. We also highlight recent advances in efforts to combat RSV infection, including the development of vaccines, monoclonal antibodies and small-molecule fusion inhibitors. We conclude with a perspective on what the next few years may hold for RSV research and clinical interventions.

\section{The virion}

The RSV genome is $15.2 \mathrm{~kb}$ and contains 10 genes encoding 11 proteins (FIG. 1). The M2 gene has two overlapping ORFs, generating both M2-1 (a transcription processivity factor) ${ }^{21,22}$ and M2-2 (a protein that governs the switch from transcription to genome replication ${ }^{23}$. The first two transcribed genes are the nonstructural proteins NS1 and NS2, which together inhibit apoptosis ${ }^{24}$ and interferon responses ${ }^{25}$. A major difference between the genomes of the Orthopneumovirus and Metapneumovirus genera is the absence of these two genes in viruses belonging to the latter.

The RSV virion contains a lipid bilayer displaying the fusion (F), attachment $(\mathrm{G})$ and small hydrophobic ( $\mathrm{SH}$ ) proteins (FIG. 1 a). The $\mathrm{F}$ and $\mathrm{G}$ proteins are in greater abundance than the $\mathrm{SH}$ protein, which is a pentameric ion channel thought to be involved in delaying apoptosis in infected cells ${ }^{26,27}$. The viral envelope is supported by a layer of matrix (M) and M2-1 proteins. The M protein is a non-glycosylated structural protein lining the inner leaflet of the viral envelope, and it associates with the cytoplasmic domain of the $\mathrm{F}$ protein $^{28-31}$. M2-1 mediates the association between M and the enclosed ribonucleoprotein complexes (RNPs) comprising viral genomic RNA tightly associated with nucleoprotein $(\mathrm{N})^{32,33}$. Also associated with the RNP is the RNA-dependent RNA polymerase complex (RdRp) composed of the large polymerase subunit (L), a phosphoprotein polymerase cofactor $(\mathrm{P})$ and $\mathrm{N}$.

\section{Glycoprotein synthesis and structure}

$\mathrm{G}$ and $\mathrm{F}$ are the major glycoproteins on the surface of the virion and have important roles in entry. The G glycoprotein functions primarily as an attachment protein that binds virions to target cells by interacting with one or more host cell surface molecules. The F glycoprotein can also facilitate attachment, although to a lesser extent than $\mathrm{G}$, but its primary function is to mediate fusion of the viral and host cell membranes. By contrast, the $\mathrm{SH}$ protein is not incorporated at substantial levels into budding filaments $\mathrm{s}^{34}$ and is dispensable for entry $\mathrm{y}^{35}$; therefore, it is not further discussed in this section.

Attachment glycoprotein. The G protein is produced in infected cells as either a full-length, membranebound form that is responsible for viral attachment ${ }^{36}$ or as a secreted isoform ( $\mathrm{sG}$ ) that mediates immune eva$\operatorname{sion}^{37}$ (FIG. 2). The full-length G protein is a single-pass type II integral membrane protein that is synthesized as

a

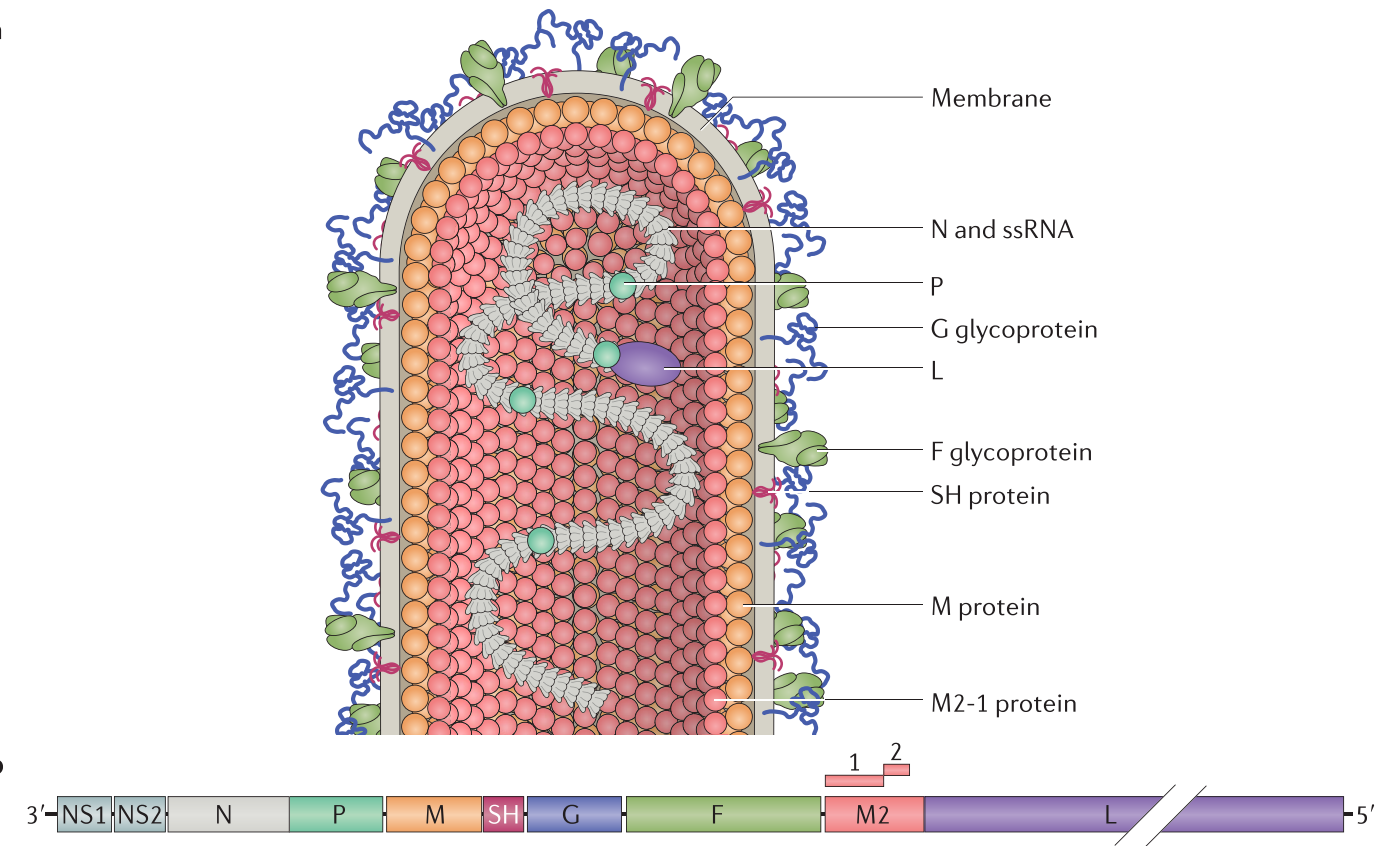

b

Fig. 1 | Respiratory syncytial virus virion. a | The filamentous morphology of the virion is shown. The attachment (G) and fusion (F) glycoproteins are embedded in the viral membrane, as is the small hydrophobic (SH) protein, which functions as a viroporin. A layer of matrix (M) protein lies underneath the viral membrane and gives the virion its filamentous shape. The M2-1 protein - a transcription processivity factor - interacts with both M protein and the nucleoprotein (N) encasing the viral RNA genome. The large polymerase subunit $(L)$ and the phosphoprotein polymerase cofactor $(P)$ are also associated with N. b | The respiratory syncytial virus (RSV) genome shown approximately to scale for the A2 strain. The genome contains 10 genes encoding 11 proteins, with the M2 gene encoding the M2-1 and M2-2 proteins. The most highly transcribed genes are those encoding nonstructural protein 1 (NS1) and NS2, which inhibit apoptosis and interferon responses. ssRNA, single-stranded RNA. 
a

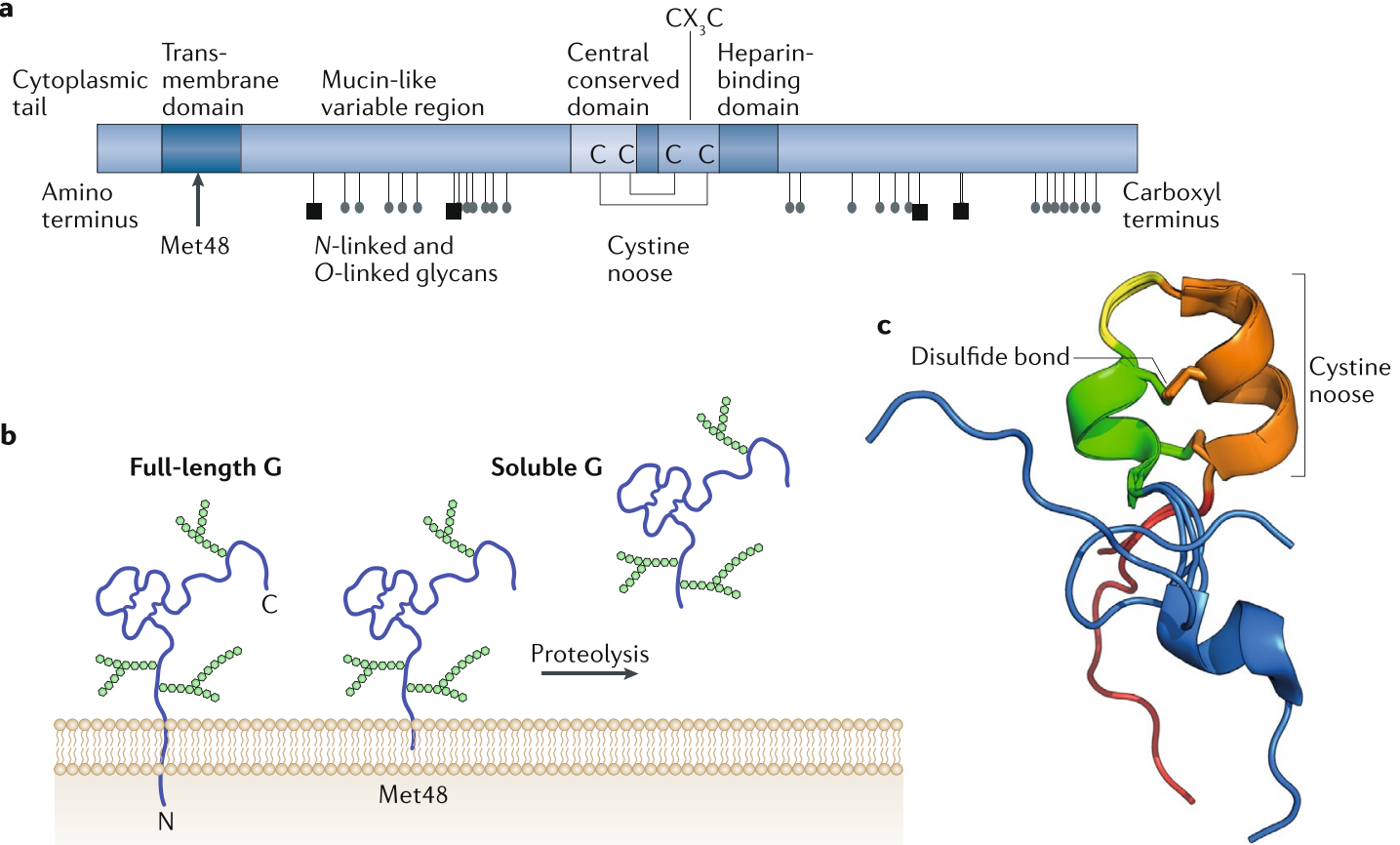

Fig. 2 | Attachment protein structure. a | Full-length respiratory syncytial virus (RSV) attachment (G) protein domains and post-translational modifications. b | Schematic of the two RSV G isoforms. Several O-linked glycans are represented by chains of green hexagons. $\mathbf{c}$ Superposition of the cystine noose and flanking regions derived from four crystal structures of RSV G-derived peptides in complex with different antigen-binding fragments (Fabs). The peptide is coloured following the spectrum from blue (amino terminus) to red (carboxyl terminus). The two disulfide bonds in the cystine noose are shown as sticks linking the helices.

an $\sim 300$-amino-acid polypeptide ${ }^{38}$, although the exact length varies by strain. The amino-terminal cytosolic domain contains a single, unpaired, cysteine adjacent to the transmembrane domain that is post-translationally palmitoylated $^{39}$. The ectodomain consists of two large, sequence-variable, mucin-like domains flanking a central conserved region and a heparin-binding domain (FIG. 2a). The mucin-like domains are predicted to be disordered and contain an amino acid composition of $\sim 30-35 \%$ serine and threonine residues and $\sim 8-10 \%$ proline residues ${ }^{38}$. The $\mathrm{G}$ protein ectodomain is post-translationally modified with $4-5 \mathrm{~N}$-linked glycans and 30-40 O-linked glycans that constitute $\sim 60 \%$ of the molecular mass of the mature glycopro$\operatorname{tein}^{38,40}$. Depending on the producing cell, different molecular masses and oligomeric forms of $G$ have been observed $^{41,42}$. The $\mathrm{sG}$ form arises owing to translation initiation at an alternative AUG codon, which, in the full-length $G$ protein, encodes Met48, located in the middle of the transmembrane domain ${ }^{43}$. A subsequent proteolytic event removes the remaining portion of the transmembrane domain, enabling the ectodomain to be secreted from the cell ${ }^{44}$ (FIG. 2b). The $s G$ has been demonstrated to act as an antigen decoy for G-directed antibodies and to decrease the Fc-mediated antiviral activity of leukocytes ${ }^{45,46}$, although there may be other roles that have not yet been discovered. A more thorough understanding of sG function could be particularly important for the development of passively administered G-directed monoclonal antibodies.
The sequence of the 26-amino-acid central conserved region has some strain-dependent variation yet contains 13 strictly conserved amino acids that partially overlap with a cystine noose domain. The reason for the strict conservation of these 13 residues remains unknown. The cystine noose contains four cysteines forming two disulfide bonds with a $1-4,2-3$ topology $y^{47,48}$, with the third and fourth cysteines in this arrangement forming a $\mathrm{CX}_{3} \mathrm{C}$ motif. Structures of 32-amino-acid and 16-amino-acid synthetic peptides derived from the central region of bovine RSV G and human RSV G, respectively, have been determined by NMR studies ${ }^{49,50}$. The cystine noose present in these structures adopts a conserved fold that is also observed in the fourth subdomain of the tumour necrosis factor receptor (TNFR) ${ }^{51}$. In the past year, two groups determined four high-resolution $\mathrm{X}$-ray crystal structures of neutralizing antibodies bound to human RSV G-derived peptides ${ }^{52,53}$. Although the cystine noose was structurally conserved with minor flexibility at the tip of the noose, multiple conformations of the highly conserved amino-terminal flanking region were observed, suggesting that this region is flexible and generally unstructured (FIG. 2c).

The $\mathrm{G}$ protein is the most variable structural protein among RSV isolates, and its sequence has been used in numerous epidemiological and evolutionary studies $\left(\right.$ reviewed elsewhere $\left.{ }^{54}\right)$. This variability, primarily localized to the mucin-like domains, dictates the RSV antigenic groups (termed RSV-A and RSV-B). These groups have also been referred to as subtypes or subgroups because the original RSV serology studies identified 


\section{REVIEWS}

a

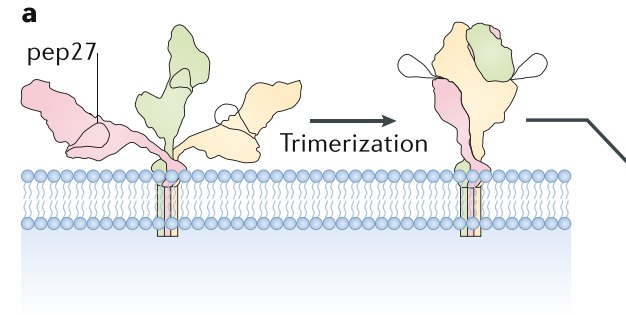

First step of furin processing

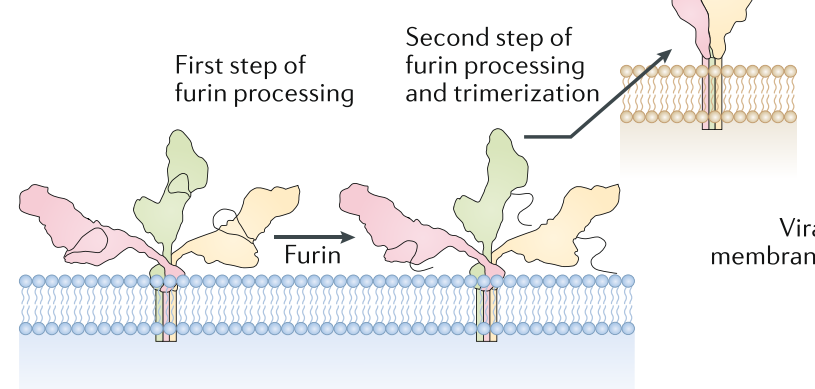

Furin

processing

$\searrow$

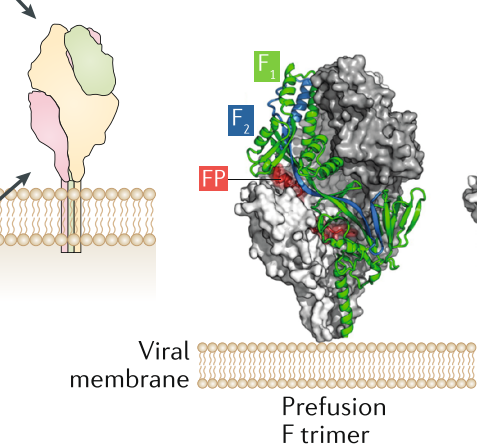

b

F trimer
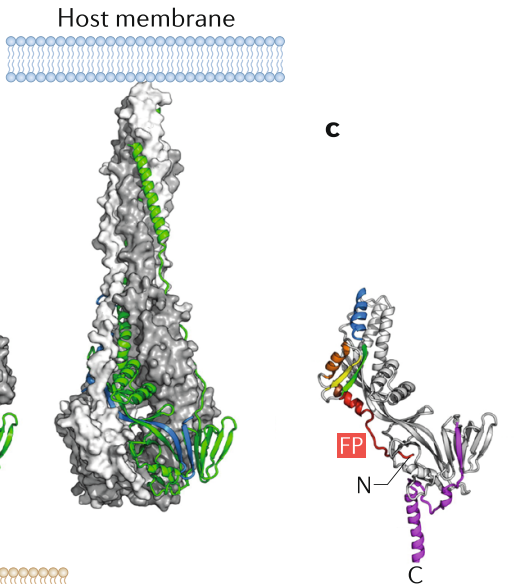

Postfusion

F trimer
Prefusion
F protomer

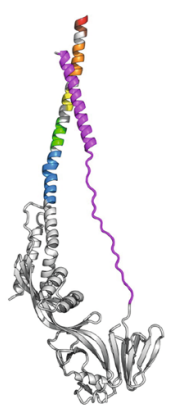

Postfusion

F protomer

Fig. 3 | Fusion protein structure. a | Schematic of fusion (F) glycoprotein maturation. F is initially synthesized as an inactive monomer containing peptide 27 (pep27). To adopt the functional prefusion conformation, pep27 must be removed by proteolysis owing to a furin-like protease, and the monomers must associate into the compact trimer. The order of events has not been definitively determined, although data favour furin processing before trimerization. b|Prefusion and postfusion trimers. Two protomers are shown as molecular surfaces coloured grey and white, whereas the third protomer is shown as a ribbon with the $F_{2}$ subunit coloured blue, $F_{1}$ coloured green, and the fusion peptide (FP) at the amino terminus of $F_{1}$ coloured red. $c \mid$ Prefusion and postfusion protomers shown as ribbons. Secondary structure elements that are in different conformations or positions between the two states are coloured. Parts $\mathbf{b}$ and $\mathbf{c}$ are adapted with permission from REF. ${ }^{182}$, Elsevier.

only a single serotype with two distinct antigenic profiles $^{55,56}$. During annual epidemics, RSV strains of different groups commonly co-circulate, with group RSV-A viruses predominating in most years ${ }^{57}$. Over the past 20 years, duplication events in the RSV G ectodomain have generated emergent RSV genotypes that have been detected globally, including the Buenos Aires genotype (BA) in 1999 and the Ontario genotype (ON1) in 2010. The BA genotype is distinct from other RSV-B genotypes in having a 60-nucleotide duplication arranged as a tandem repeat insertion in the second mucin-like domain near the carboxyl terminus ${ }^{58}$. Following its first isolation, the BA genotype has spread globally and replaced the circulating RSV-B strains in certain regions ${ }^{59,60}$. The ON1 genotype is distinct from its ancestral RSV-A genotype in having a 72-nucleotide tandem repeat insertion in the carboxy-terminal mucin-like domain ${ }^{61}$. The ON1 genotype has spread and diversified globally at an even more rapid rate than the BA genotype ${ }^{62,63}$. The rapid global spread of these emergent genotypes suggests that these duplication events provide a selective advantage, which may be due to an increase in viral attachment ${ }^{64}$, steric masking of the F glycoprotein from neutralizing antibodies ${ }^{65}$ or another mechanism that has yet to be determined.

Fusion glycoprotein. The RSV F protein is a class I viral fusion glycoprotein that shares structural similarities with Paramyxoviridae F glycoproteins ${ }^{66,67}$ despite limited sequence similarity. RSV F is synthesized as a 574-amino-acid polypeptide called $\mathrm{F}_{0}$ that is post-translationally modified with 5 or $6 \mathrm{~N}$-linked glycans, depending on the strain ${ }^{68}$. To become fusion competent, F must be cleaved at two polybasic sites that are separated by 27 amino acids (peptide 27; pep27) containing 2 or $3 \mathrm{~N}$-linked glycans ${ }^{69,70}$ (FIG. 3a). This priming event is performed by furin-like host proteases ${ }^{71}$ in the trans-Golgi network as $\mathrm{F}$ is transported to the plasma membrane $^{72}$. The proteolysis generates two subunits, the amino-terminal $\mathrm{F}_{2}$ subunit (residues 26-109) and the carboxy-terminal $\mathrm{F}_{1}$ subunit (residues 137-574), which in their glycosylated forms are approximately $15 \mathrm{kDa}$ and $55 \mathrm{kDa}$, respectively. The $\mathrm{F}_{2}$ and $\mathrm{F}_{1}$ subunits are covalently linked through two disulfide bonds to yield a heterodimeric protomer ${ }^{73}$, three of which associate to form the mature trimeric form of the F protein. Although not yet confirmed, there is evidence to suggest that trimerization of RSV F can only occur after proteolytic activation $^{74,75}$, which would be in contrast to other class I viral fusion proteins, including the HIV-1 envelope (Env), coronavirus spike (S) and even paramyxovirus $\mathrm{F}$.

Once cleaved and trimerized, $F$ adopts the prefusion conformation, which has a spheroidal shape that reaches $\sim 12 \mathrm{~nm}$ above the viral membrane ${ }^{76}$ (FIG. 3b). The fusion peptides, located at the amino termini of the $F_{1}$ subunits, are buried inside the central cavity of the protein. This prefusion conformation of $\mathrm{F}$ is unstable and has a low energy barrier to refolding, as evidenced by the accumulation of the refolded postfusion form of the protein on the surface of virions as a function of time $\mathrm{e}^{77,78}$. During the refolding process, the fusion peptides are withdrawn from the central cavity and are projected away from the viral membrane, as secondary structure elements in the $\mathrm{F}_{1}$ subunits refold into a long $\alpha$-helix (FIG. 3c). If 
another membrane, such as a host cell membrane, is in close proximity, the fusion peptides will insert into the membrane, and the F protein will span both membranes. This conformation of $\mathrm{F}$ is referred to as the hypothetical prehairpin intermediate, in part because it has only been observed indirectly for the F protein from parainfluenza type $5\left(\mathrm{REF}^{\mathrm{T}}{ }^{79}\right)$. The $\mathrm{F}$ protein continues to refold as heptad repeat patterns in the amino termini and carboxyl termini of the $\mathrm{F}_{1}$ subunit associate, forming a trimer of hairpins that brings the two membranes together to facilitate fusion ${ }^{80}$. This refolding process is irreversible, and the postfusion conformation of $\mathrm{F}$, which stands $\sim 17 \mathrm{~nm}$ above the membrane $\mathrm{e}^{81,82}$, is extremely stable, with a melting temperature $>90^{\circ} \mathrm{C}$. The difference in free energy between the prefusion and postfusion conformations offsets the free energy needed to deform and fuse the two apposed membranes, although the number of $\mathrm{F}$ proteins required to form a fusion pore has not been determined.

Unlike the $\mathrm{G}$ protein, the sequences of $\mathrm{F}$ ectodomains differ by $\sim 5 \%$ between RSV-A and RSV-B. This lack of sequence variation in F explains the single RSV serotype and is in stark contrast to the sequence variation observed for some other class I viral fusion proteins, such as HIV-1 Env and influenza virus haemagglutinin (HA). Thus, RSV F does not undergo substantial antigenic drift as an immune-evasion strategy, despite eliciting neutralizing antibodies in people who have been infected. Consequently, a vaccine for RSV may be easier to obtain than a vaccine for HIV-1 or a universal influenza vaccine.

\section{Host cell entry}

The entry process consists of two main steps: attachment of the virion to the host cell and fusion of the viral and host cell membranes (BOX 1). Host cell factors may be involved in either one or both steps. For this Review, we define attachment factors as host cell molecules that function only to bind components of the virion, and we define functional receptors as host cell molecules that stimulate, or trigger, the refolding of F. In vivo, RSV tropism is highly restricted to the apical surface of ciliated airway epithelial cells and type I alveolar pneumocytes ${ }^{83}$, although the molecular basis for this restriction is not well understood. There have also been reports of viral RNA in extrapulmonary sites and fluids ${ }^{84-86}$, but further studies are needed to determine whether this is a result of RSV infection at these sites.

Attachment. The primary role of the $\mathrm{G}$ protein is to attach virions to cell surfaces through interaction with host cell attachment factors. The G protein has been shown to bind glycosaminoglycans (GAGs), which are unbranched disaccharide polymers linked to transmembrane proteins on the surface of many mammalian cell types ${ }^{87,88}$. This interaction is primarily mediated by a stretch of positively charged amino acids located between the two mucin-like domains of G, referred to as the heparin-binding domain ${ }^{89}$. However, variants of $\mathrm{G}$ lacking the heparin-binding domain retain some heparinase-sensitive binding to cells, suggesting that other regions of $\mathrm{G}$ may bind weakly to $\mathrm{GAGs}^{87}$.
Negatively charged regions of heparan sulfate are considered to be the primary attachment points ${ }^{88,90,91}$, although other iduronic-acid-containing GAGs may contribute to a lesser extent ${ }^{92}$. There are, however, conflicting reports as to the abundance of heparan sulfate on the apical surface of ciliated, well-differentiated human airway epithelial cells $^{93,94}$, which are the principal sites of RSV replication during natural infection ${ }^{95}$. Thus, although GAGs mediate interactions with $\mathrm{G}$ on the surface of immortalized cells, these interactions may not be physiologically relevant ${ }^{96}$.

Another host cell attachment factor thought to interact with $\mathrm{G}$ is the fractalkine receptor $\mathrm{CX}_{3} \mathrm{C}$-chemokine receptor $1\left(\mathrm{CX}_{3} \mathrm{CR} 1\right)$. An analysis of the amino acid sequence of $\mathrm{G}$ identified a $\mathrm{CX}_{3} \mathrm{C}$ motif that is also found in the chemokine fractalkine, the natural ligand for $\mathrm{CX}_{3} \mathrm{CR} 1\left(\mathrm{REF}^{\mathrm{9}}{ }^{7}\right.$ ). Like $\mathrm{G}$, fractalkine is tethered to the membrane by a mucin-like domain and can be found as a soluble protein due to proteolysis ${ }^{98}$. Various lines of investigation of both immortalized and human airway epithelial cells - including flow cytometry, fluorescence microscopy, chemotaxis and RSV infection - have suggested an interaction between $\mathrm{G}$ and $\mathrm{CX}_{3} \mathrm{CR} 1$ that is mediated by the $\mathrm{CX}_{3} \mathrm{C}$ motif in the cystine noose $\mathrm{e}^{93,96,97,99}$. However, a direct interaction using purified components has not been demonstrated. Moreover, the structures of fractalkine and the G cystine noose do not adopt the same fold ${ }^{52}$, and the disulfide-bond arrangement in fractalkine $(1-3,2-4)$ is different from that in $\mathrm{G}(1-4,2-3)$. Thus, the precise role of $\mathrm{CX}_{3} \mathrm{CR} 1$ in RSV entry remains to be defined.

Although $G$ facilitates attachment of virions to the host cell surface, RSV variants lacking both G and SH grow well in cell culture ${ }^{100,101}$, implying a role for the F protein in attachment. Like $G$, the F protein has been demonstrated to interact with immobilized heparin or cellular heparan sulfate, promoting attachment to and infection of immortalized cells ${ }^{102}$. Virions containing only $\mathrm{F}$ on the surface retain $\sim 50 \%$ of their infectivity for cells treated with heparinase or deficient in GAG synthesis, suggesting that $\mathrm{F}$ also interacts with one or more non-GAG attachment factors. Several proteins have been proposed to interact with $\mathrm{F}$ and facilitate RSV entry, including intercellular adhesion molecule 1 $(\mathrm{ICAM} 1)^{103}$, epidermal growth factor receptor (EGFR) ${ }^{104}$ and nucleolin ${ }^{105}$. Of these, the data for nucleolin are the strongest, and nucleolin has been shown to interact with many other viruses, including parainfluenza type $3(\mathrm{PIV}-3)^{106}$, enterovirus $71\left(\mathrm{REF}^{107}\right)$, Crimean-Congo haemorrhagic fever virus ${ }^{108}$, adeno-associated virus type $2(\mathrm{AAV}-2)^{109}$ and HIV-1 (REF. ${ }^{110}$ ). Given the promiscuity of nucleolin, it is likely to function as an attachment factor for RSV F, as opposed to acting as a functional receptor. It should also be noted that for all the putative attachment factors, none has been demonstrated biochemically or biophysically to interact directly with F using purified components.

Membrane fusion and regulation. After attachment, fusion of the viral and host cell membranes must occur for the RNP to enter the cytoplasm. On the basis of experiments demonstrating that fusion is $\mathrm{pH}$-independent and insensitive to lysosome acidification ${ }^{111,112}$ and that 


\section{Box 1 The life cycle of respiratory syncytial virus}

The infectious cycle of respiratory syncytial virus (RSV) begins upon attachment of the virion to the apical surface of polarized, ciliated airway epithelial cells ${ }^{95}$ (see the figure). The viral attachment (G) glycoprotein associates with cell surface factors and facilitates the initial attachment $\operatorname{step}^{36,163}$. Viral entry is facilitated by the viral fusion (F) glycoprotein ${ }^{68}$ a trimeric class I fusion protein that drives fusion of the viral and host cell membranes by undergoing a drastic conformational change ${ }^{76,164}$. After fusion, the helical ribonucleoprotein complex (RNP) is released into the host cell cytoplasm. Transcription and replication occur in the cytoplasm in viral inclusion bodies that serve to concentrate viral products ${ }^{165-167}$. The viral RNA-dependent RNA polymerase (RdRp) complex is responsible for transcribing viral mRNA and synthesizing positive-sense anti-genome intermediates needed for replication of new negative-sense genomes for packaging into virions (reviewed elsewhere ${ }^{168}$ ). In addition to performing non-proofreading polymerase functions, the RdRp caps and polyadenylates viral mRNAs.

Assembly of RSV virions occurs at or near the plasma membrane ${ }^{169,170}$. Initial models posited that $F$ proteins associate with lipid rafts and, through the $F$ cytoplasmic tail, recruit and concentrate matrix (M) proteins; this process initiates filament budding through actin-dependent outward membrane deformation ${ }^{31,77,171}$. Recent cryo-electron tomography studies have provided support for this model through the visualization of filament assembly and budding at the plasma membrane ${ }^{170}$. However, other experiments have suggested that this process may be more complex, with filament formation initially occurring intracellularly as vesicles containing viral proteins traffic along microtubules and grow into filaments that are then loaded with nucleocapsid before merging with the plasma membrane through an unknown mechanism ${ }^{172}$. After budding from the apical membrane of polarized epithelial cells, virions detach and are released in a M-dependent maturation process as filamentous particles $\sim 130 \mathrm{~nm}$ in diameter and $0.5-12$ micrometres in length ${ }^{170,173,174}$. Over time, the $\mathrm{M}$ layer dissociates from the viral membrane, creating non-filamentous regions in the virion that ultimately lead to spherical or pleiomorphic particles that are thought to be less infectious, likely owing to a premature conversion of the F protein from the prefusion to postfusion conformation ${ }^{77,78}$. HSPG, heparan sulfate proteoglycan.

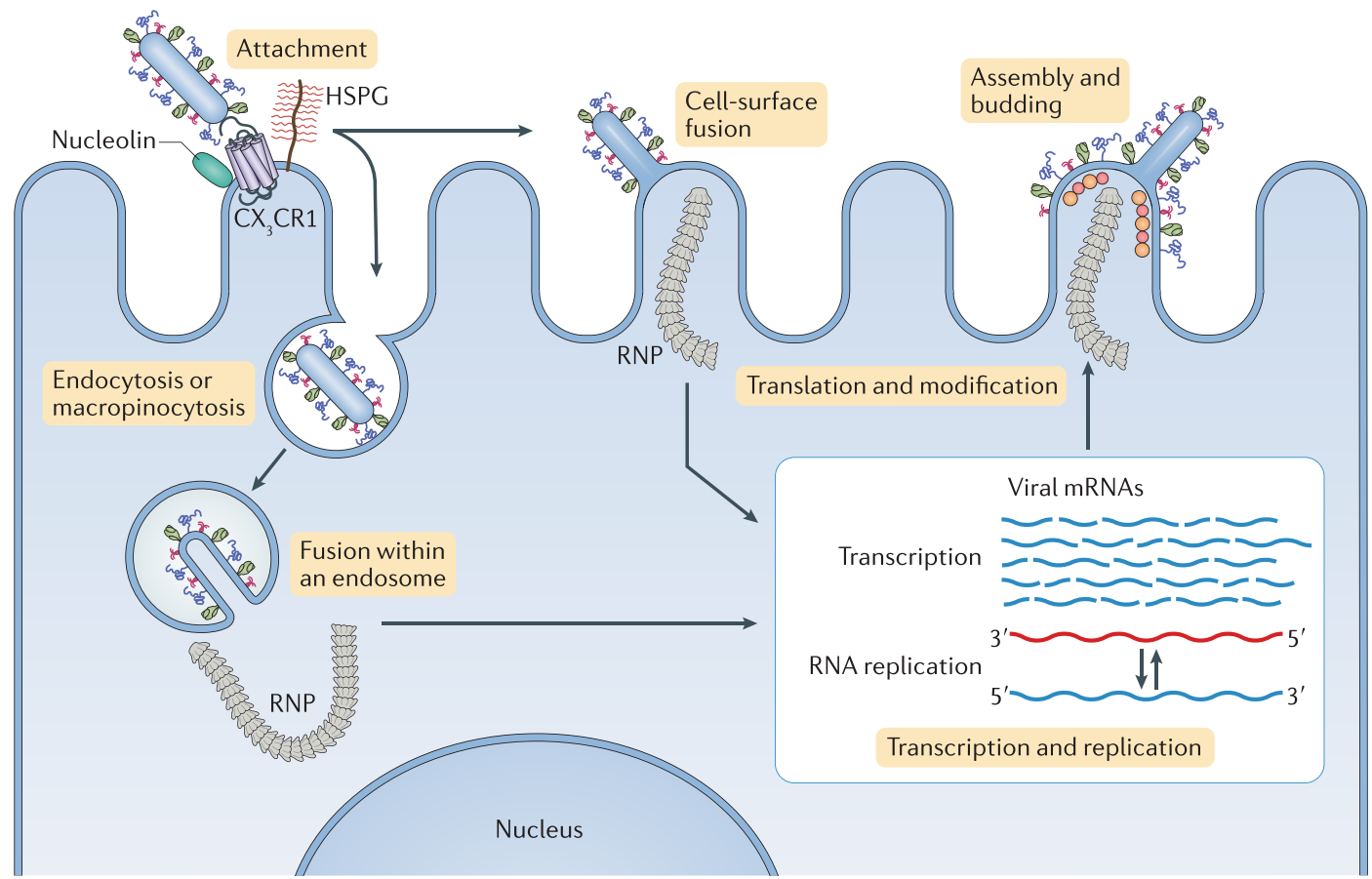

RSV-infected cells can fuse with neighbouring cell membranes to generate multinucleated cells called syncytia ${ }^{2}$, RSV fusion was thought to occur at the plasma membrane. However, this interpretation assumed that viruses utilizing endocytic pathways for fusion require low $\mathrm{pH}$ for infectious entry. Since those initial RSV fusion experiments, a variety of mechanisms for viral endocytic entry have been defined, some of which are $\mathrm{pH}$-independent or require only low $\mathrm{pH}$ for the activity of an endosomal protease (reviewed elsewhere ${ }^{113}$ ). A more recent report indicated that the initial steps of RSV fusion occur at cholesterol-rich microdomains in the plasma membrane, with completion of membrane fusion possibly requiring a dynamin-independent endocytic event ${ }^{114}$. A subsequent study demonstrated that RSV utilizes macropinocytosis as an initial entry mechanism followed by fusion in endosomes ${ }^{115}$. Thus, the evidence now suggests either a two-step fusion event or fusion in endosomes after macropinocytosis. However, it may be the case that RSV can fuse at both the plasma membrane and in endocytic vesicles, with different efficiencies depending on environmental conditions and target cells.

Although some questions remain about the location of RSV fusion, there is even less known about the event that initiates, or triggers, fusion. For class I viral fusion proteins, three triggers have been well defined: low $\mathrm{pH}$, as is the case for influenza virus HA; direct receptor binding, as used by HIV-1 Env; and provocation by a second viral glycoprotein, which is the mechanism for paramyxovirus F proteins (BOX 2). As mentioned above, 
Box 2 | Paramyxovirus entry

The genomes of paramyxoviruses and pneumoviruses encode similar proteins, and until recently, both types of virus were classified in the same family — Paramyxoviridae. However, unlike Pneumoviridae G proteins, which are highly $\mathrm{O}$-glycosylated, structurally flexible and poorly conserved in the large mucin-like domains, Paramyxoviridae attachment proteins (referred to as $\mathrm{HN}, \mathrm{H}$ or $\mathrm{G}$ proteins) are tetramers of a six-bladed $\beta$-propeller head and helical stalk that are structurally and functionally conserved across Paramyxoviridae (reviewed elsewhere ${ }^{119,175}$ ). Paramyxovirus attachment proteins bind various substrates on the surface of target cells, such as sialic acid, or proteinaceous receptors, such as ephrin type-B receptor 2 (EPHB2) and/or EPHB3 or NECTIN4. The receptor engagement triggers the membrane fusion process through interactions between the homotypic attachment and fusion (F) proteins. The fusion proteins of paramyxoviruses and pneumoviruses are structurally similar, although there are differences, such as the position of the fusion peptides, disulfide bonds and $\mathrm{N}$-linked glycosylation sites.

The 'provocateur' model has coalesced as the most comprehensive model for the spatiotemporal regulation of paramyxovirus membrane fusion, supplanting the alternative 'clamp' or dissociation model (reviewed elsewhere ${ }^{119,175}$ ). In the provocateur model (see the figure), the binding of a cellular receptor to the receptor-binding domain head of the tetrameric attachment protein results in a conformational change that, in a two-step process, first exposes the four-helix bundle stalk domain, enabling association with $F$, and then triggers membrane fusion by lowering the activation energy required to initiate $\mathrm{F}$ refolding through $\mathrm{F}$-stalk interactions. Crystal structures of various paramyxovirus attachment proteins have revealed the beginning (four heads down) ${ }^{176}$, intermediate (two heads up and two heads down) ${ }^{177}$ and end (four heads up) ) $^{117}$ states of the conformational changes in the tetrameric head domains associated with the unveiling of the stalk domain. Compelling evidence for the provocateur model comes from experiments utilizing 'headless' stalk constructs that have been observed to constitutively activate conformational changes in $\mathrm{F}^{178-180}$. In addition, certain residues on the surface of the Newcastle disease virus or parainfluenza virus $5 \mathrm{HN}$ stalk have been shown to specifically disrupt fusion activation $^{176}$, presumably through direct interactions with the $\mathrm{F}$ protein (reviewed elsewhere ${ }^{181}$ ). Thus, although a number of outstanding questions remain, the molecular mechanisms governing the spatiotemporal regulation of Paramyxoviridae fusion activation have a solid basis in experimental evidence and appear to be conserved across this family of viruses.

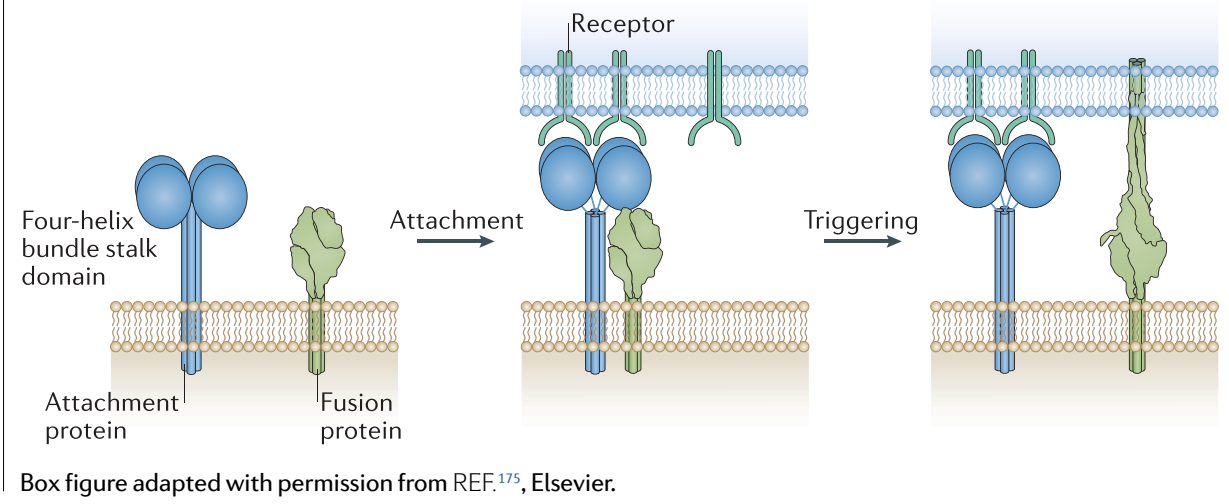

there is substantial evidence to support $\mathrm{pH}$-independent triggering of RSV F. Receptor-induced triggering remains a possibility, although a host cell molecule that stimulates refolding of $\mathrm{F}$ has not been identified to date. Evidence for such a molecule was suggested in an article from 2003 that reported that human RSV infects human but not bovine primary cells, whereas bovine RSV infects bovine but not human primary cells ${ }^{116}$. Using chimeric viruses, the species tropism was attributed to the $\mathrm{F}_{2}$ subunit. However, to our knowledge, these data were neither pursued further nor independently verified. The third option, provocation by a second viral glycoprotein, appears unlikely given that virions lacking both the $G$ and $\mathrm{SH}$ proteins are infectious and grow to high titres in culture. Furthermore, unlike the attachment proteins of paramyxoviruses, which have tertiary and quaternary structure $^{117,118}$, the G proteins of RSV and the related hMPV are predicted to be mostly disordered ${ }^{65}$. This lack of structure would make it difficult to transduce a binding event from the $G$ protein to the $F$ protein. A fourth mechanism, originally proposed for certain paramyxoviruses, is known as the clamp model (reviewed elsewhere ${ }^{119}$ ), whereby the $\mathrm{G}$ protein binds to and prevents spontaneous triggering of the $\mathrm{F}$ protein until engagement of the $G$ protein by a host cell receptor. The ability of viruses lacking the $G$ protein to grow to high titres in cell culture disfavours this mechanism for RSV F.

An alternative hypothesis is that RSV lacks spatiotemporal control of $\mathrm{F}$ protein triggering. The benefit of triggering at the proper time and place is that all fusion proteins remain functional until the possibility of a productive fusion event is maximized. However, it may not be necessary for all viruses to be so efficient. It is well documented that the prefusion conformation of RSV F is unstable and converts to the postfusion form at some basal rate ${ }^{77}$. As expected, both longer incubation times and incubation at elevated temperatures increase the conversion to the postfusion conformation ${ }^{78,120}$. Therefore, it is possible that the basal rate of spontaneous conversion to the postfusion form is sufficient for RSV entry once attachment by $\mathrm{G}$ or $\mathrm{F}$ brings the target cell membrane into close apposition with refolding $F$ proteins (FIG. 4). Evidence for this model would likely require fusion reconstitution experiments with liposomes or supported lipid bilayers in which the composition of the target membrane could be carefully controlled. 


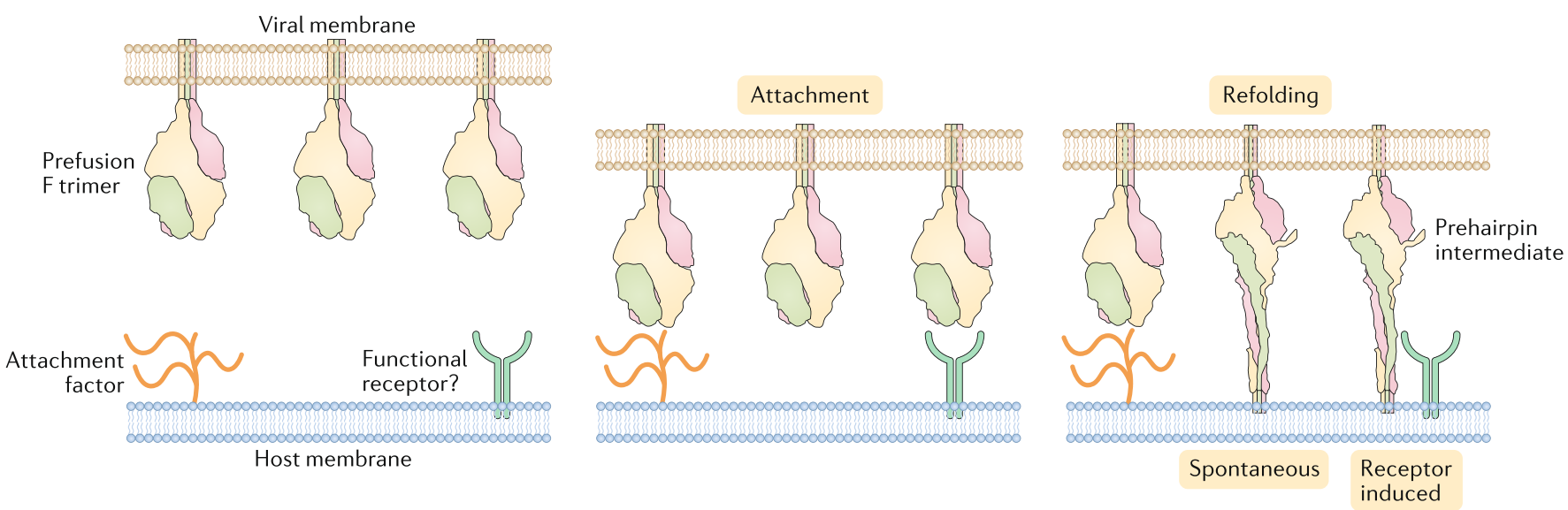

Fig. 4 | Attachment and fusion. The fusion (F) protein can interact with one or more attachment factors to bind the virus to the host cell, a process that is greatly enhanced by the viral attachment protein (not shown). The F protein may also interact with a functional receptor that induces refolding of the prefusion conformation to the prehairpin intermediate. Alternatively, or in addition, the $\mathrm{F}$ protein spontaneously refolds at a basal rate.

\section{Clinical interventions}

Preclinical and clinical development of RSV interventions primarily falls into three categories: monoclonal antibodies, small molecules and vaccines. These modalities have their own unique advantages and disadvantages, but promising candidates for each are in clinical trials. These include viral RdRp inhibitors (reviewed elsewhere ${ }^{121}$ ), but because these compounds do not block entry, they are not discussed here.

Antibodies. High levels of RSV-neutralizing-antibody titres correlate with protection in children and adults, including elderly individuals ${ }^{4,122,123}$. An RSV intravenous immune globulin infusion preparation, RespiGam, was used prophylactically in the late 1990s and early 2000s to prevent severe RSV-associated lower respiratory tract disease in young children with bronchopulmonary dysplasia or premature birth ${ }^{124}$. The use of RespiGam was discontinued in 2003 and replaced by prophylaxis with palivizumab (Synagis), a humanized murine monoclonal antibody that binds the F glycoprotein ${ }^{125}$. Palivizumab recognizes an epitope within antigenic site II, which is preserved on both the prefusion and postfusion F conformations ${ }^{126}$ (FIG. 5a). As palivizumab does not prevent triggering of conformational changes in F, it presumably blocks entry and membrane fusion by preventing conversion of the prehairpin intermediate into the postfusion conformation. As with RespiGam, palivizumab is used for prophylaxis only for high-risk infants because of its cost and limited efficacy ${ }^{20}$.

As a result of tremendous advances in monoclonalantibody-isolation technology, during the past 10 years, hundreds of human-derived antibodies directed against the RSV F and G proteins have been isolated and characterized $^{127-132}$. Some of the F-directed antibodies are 10-50-fold more potent than palivizumab, and many of them recognize epitopes located exclusively on the prefusion conformation. Consequently, these prefusionspecific antibodies are able to lock $\mathrm{F}$ in its prefusion conformation and prevent conversion to the prehairpin intermediate ${ }^{76}$. One such human antibody, called D25, which recognizes antigenic site $\varnothing$, was optimized to produce a variant, MEDI8897, with enhanced potency and extended serum half-life ${ }^{133}$. Owing to these improvements, MEDI8897 may require only a single dose during the RSV season to prevent severe disease in infants, and results from a phase IIb clinical study were expected in late 2018 (REF. ${ }^{134}$ ). However, a different prefusion-specific antibody, REGN2222, which recognizes antigenic site $\mathrm{V}$, recently failed to reach its clinical end points in a phase III study ${ }^{135}$, and the reasons for the failure are not yet known. Other prefusion-specific antibodies are also in preclinical development, as are antibodies directed against the $G$ protein that inhibit viral attachment ${ }^{52,53}$. Cocktails of antibodies against F and G, or against two different antigenic sites on $\mathrm{F}$, are also being considered and may lead to synergistic effects and reduced viral escape.

Small-molecule fusion inhibitors. Phenotypic screening of targeted chemical libraries identified several structurally distinct molecules that inhibited RSV fusion with target cells (reviewed elsewhere ${ }^{136,137}$ ). On the basis of crosslinking studies with RSV virions ${ }^{138}$ and biochemical and structural studies with peptides comprising the heptad repeats of the RSV $F_{1}$ subunit $^{139}$, it was thought that the small molecules bound to a fusion intermediate of $\mathrm{F}$ and prevented the postfusion conformation from completely forming. However, once the prefusion and postfusion F protein crystal structures were determined, the escape mutations for these molecules were found to cluster inside the central cavity of the prefusion conformation, whereas in the postfusion conformation, they were separated by $\sim 100$ angstroms ${ }^{140}$ (FIG. 5b). Crystallographic experiments later revealed that the small molecules bind inside the central cavity of the prefusion conformation and interact with residues in the fusion peptide and the second heptad repeat $^{141}$. Functional studies with soluble F proteins ${ }^{142}$ and membrane-bound F proteins ${ }^{141}$ demonstrated that the small molecules function as antagonists that prevent 
a

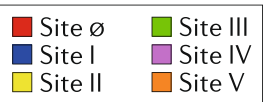

Prefusion $\mathrm{F}$ trimer

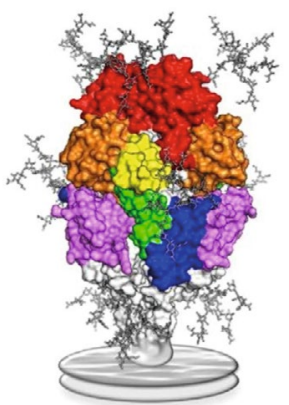

b

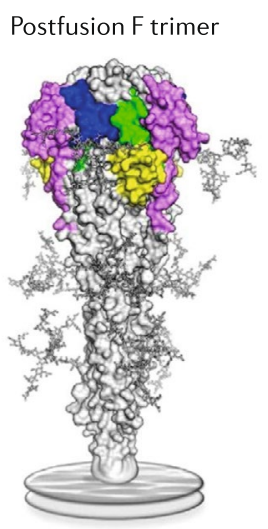

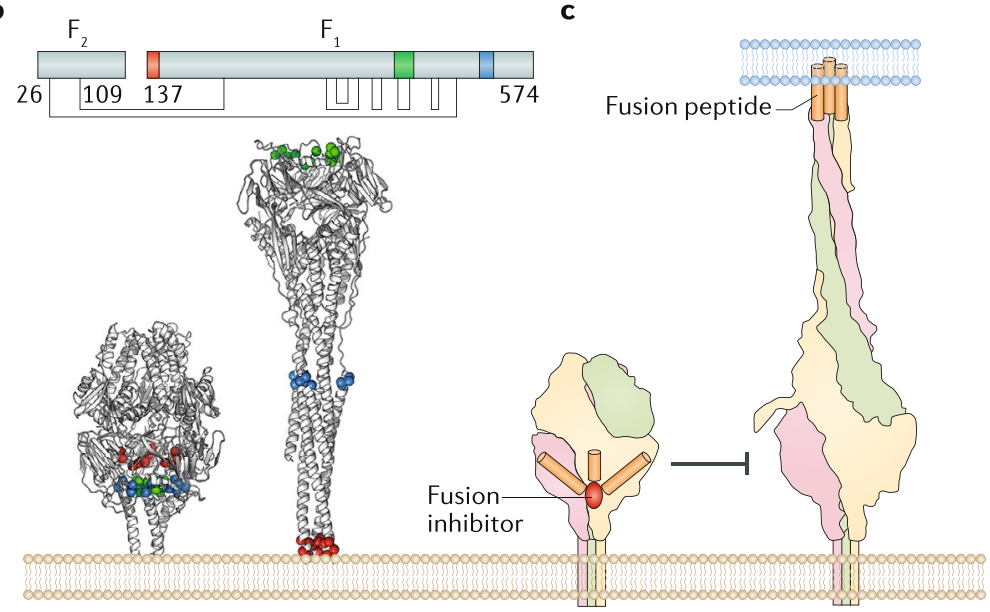

Fig. 5 | Fusion protein binding sites for antibodies and small molecules. a | Location of the major antigenic sites on the prefusion and postfusion conformations of the respiratory syncytial virus (RSV) fusion (F) protein as defined in REF. ${ }^{129}$. Modelled complex-type $\mathrm{N}$-linked glycans are shown as sticks. $\mathbf{b}$ | Escape mutations of the fusion inhibitors map to three distinct regions of the RSV F protein primary amino acid sequence, coloured red, green and blue. The positions of the escape mutations are shown as coloured spheres on ribbon diagrams of the prefusion (left) and postfusion (right) conformations. $\mathbf{c}$ |Schematic representation of the prefusion (left) and prehairpin intermediate (right) conformations depicting the location of the fusion peptides (cylinders) and fusion-inhibitor binding site (red oval). Small-molecule fusion inhibitors bind inside the central cavity of the prefusion $\mathrm{F}$ conformation and interact with the fusion peptides, preventing their release and insertion into host cell membranes. Part $\mathbf{a}$ is adapted with permission from REF. ${ }^{146}$, Elsevier.

triggering of the prefusion conformation. To date, all known RSV small-molecule fusion inhibitors bind in the same pocket and have the same mechanism of action (FIG. 5c).

Fusion inhibitors GS-5806 (presatovir) and JNJ53718678, developed by Gilead Sciences and Janssen Pharmaceuticals, respectively, have both performed well in phase II double-blind, placebo-controlled, human-challenge studies. Oral administration of either compound led to a reduction in viral load and disease severity among healthy adults experimentally infected intranasally with a clinical isolate of RSV ${ }^{143,144}$. The participants were administered the fusion inhibitors either 5 days after inoculation or at the time of a positive test for RSV, demonstrating that these compounds could be used for treatment of an upper respiratory tract infection if administered soon after infection. Of course, protecting the lower respiratory tract of infants in a natural-infection setting will likely prove to be more difficult than the proof-of-principle adult challenge studies described above, and these fusion inhibitors will need to be evaluated in the paediatric population.

A concern for RSV fusion inhibitors is the ease at which escape variants in the F protein arise in cell culture experiments ${ }^{140}$. Many of these variants, however, have reduced fitness in cell culture growth assays, reaching titres approximately 100 -fold lower than those of the wildtype virus 48 hours post-infection ${ }^{141}$. Presently, the degree to which escape variants may arise in humans treated with fusion inhibitors is unknown, as is the effect that the emergence of such variants would have on clinical outcomes. With high-resolution structural information available for many of these compounds, it may now be possible to design next-generation inhibitors that are more resistant to escape or that bind to a different site on the F protein so that cocktails of fusion inhibitors could be used to suppress the outgrowth of escape variants. A better understanding of the mechanisms of escape from these fusion inhibitors would also aid these efforts.

Vaccines. RSV vaccine development has become more sophisticated owing to recent advances in our understanding of the structure and function of the viral proteins, the morphology and architecture of the virion, the immune responses to natural infection and the causes of vaccine-enhanced disease. These advances have created a complex vaccine landscape with over 30 candidates in clinical or preclinical development comprising six different vaccine modalities each targeting one or more of the three major target populations (reviewed elsewhere $\left.^{145,146}\right)$.

Particle-based and subunit-based vaccines are intended for elderly people or maternal immunization owing to concerns that these vaccines may cause vaccine-enhanced disease in RSV-naive infants. The $\mathrm{F}$ protein is the primary antigen for these modalities, although some virus-like particles also contain the $G$ protein, and a few subunit-based vaccines consist of only the $\mathrm{G}$ protein. Approximately 5 years ago, researchers demonstrated that the majority of RSV-neutralizing activity in human sera is specific for the prefusion conformation of $\mathrm{F}^{147}$, and many of the most potent antibodies specifically target this conformation ${ }^{129,148}$. As a result, vaccine development of candidates containing the F protein has focused on structure-based engineering approaches to stabilize $\mathrm{F}$ in the prefusion conformation $^{75,149}$, and animal studies have shown that prefusion $\mathrm{F}$ elicits higher neutralizing antibody titres than does postfusion F. Currently, several prefusion F-subunit vaccine candidates are in phase I clinical trials ${ }^{150,151}$, and results 
are expected to be announced in 2019. Candidates containing postfusion $\mathrm{F}$, or molecules with the postfusion F morphology, have failed in several recent late-stage clinical trials ${ }^{152-154}$, but they remain under development, and one candidate is being tested in a phase III trial ${ }^{155}$. For particle-based and subunit-based vaccines intended for elderly individuals or maternal immunization, the challenge will be to induce an antibody response of sufficient titre and duration to protect elderly people and newborns from severe disease during the RSV season.

Live-attenuated and chimeric virus vaccines are primarily intended for the paediatric population because they are considered safe for RSV-naive infants given their demonstrated inability to prime for vaccine-enhanced disease (reviewed elsewhere ${ }^{156}$ ). Vaccines based on viral vectors and DNA or RNA are also thought to be safe for infants because the infants' cells produce the encoded antigen or antigens, leading to a balanced $\mathrm{T}$ cell response and display of properly folded antigens on the cell surface for antibody recognition and elicitation. There are several live-attenuated vaccine candidates in phase I trials, with the majority attenuated via deletion of viral genes such as NS2 or M2-2 (REF. ${ }^{157}$ ). New candidates in preclinical development include some that have been engineered to display prefusion-stabilized variants of the F glycoprotein ${ }^{158,159}$. Three vector-based candidates are in or have almost completed phase II trials, including two adenovirus candidates expressing either prefusion-stabilized F protein ${ }^{160}$ or F, N and M2-1 (REF. ${ }^{161}$ ) and a modified vaccinia Ankara (MVA) candidate expressing F, G, $\mathrm{N}$ and M2-1 (REF. ${ }^{162}$ ). For all live-attenuated vaccines, achieving the optimal balance between attenuation and immunogenicity will be crucial, whereas viral vector and nucleic-acid-based vaccines will need to achieve sufficient gene delivery and expression to produce a robust immune response.

\section{Conclusions and outlook}

There has been substantial progress in our understanding of RSV entry, although the basic science continues to lag behind clinical advances. Indeed, we may now be closer to having an effective RSV vaccine than we are to understanding the molecular mechanisms of RSV attachment and fusion. Future experiments should define how, or if, the $\mathrm{G}$ protein interacts with $\mathrm{CX}_{3} \mathrm{CR} 1$ and uncover new host cell attachment factors. Similarly, the interactions of $\mathrm{F}$ with $\mathrm{G}$ and $\mathrm{M}$ proteins and host cell factors will need to be biochemically and biophysically characterized. The development of reconstituted fusion assays should help to better define the minimal requirements for RSV fusion and answer outstanding questions concerning the triggering of the F protein. Structural studies of $\mathrm{F}$ protein intermediates, as well as uncleaved forms of F, will also improve our understanding of RSV fusion and may identify new targets for antibodies or small molecules.

The next few years will be an exciting time for clinical interventions. The outcome of the MEDI8897 clinical trial $^{134}$ is eagerly anticipated, as are results from clinical trials involving vaccines containing prefusion and postfusion $\mathrm{F}$ antigens. Clinical trials for fusion inhibitors, such as JNJ-53718678, are ongoing, and new trials will be started soon. For small-molecule and monoclonal-antibody interventions, which bind to a single site on the glycoproteins, the presence and distribution of naturally occurring RSV variants will need to be monitored as they could affect the results of clinical trials and long-term product efficacy. Similarly, the large-scale administration of such an intervention may select for the emergence of escape variants, as has occurred for other RNA viruses such as the influenza virus, and cocktails of more than one antibody or small molecule should be considered for development. Vaccines may also benefit from the monitoring of RSV variation, although in general, the immune responses to vaccines are diverse and target multiple viral epitopes.

It is our hope that the current optimism surrounding RSV interventions is well founded and that one or more effective interventions will be licensed during the next decade. Such an advance would have a tremendous impact on the lives of many of the world's most vulnerable populations.

Published online 5 February 2019
1. Blount, R. E. Jr, Morris, J. A. \& Savage, R. E. Recovery of cytopathogenic agent from chimpanzees with coryza. Proc. Soc. Exp. Biol. Med. 92, 544-549 (1956).

2. Chanock, R., Roizman, B. \& Myers, R. Recovery from infants with respiratory illness of a virus related to chimpanzee coryza agent (CCA). I. Isolation, properties and characterization. Am. J. Hyg. 66, 281-290 (1957).

This study reports the first isolation of RSV from infants.

3. Chanock, R. \& Finberg, L. Recovery from infants with respiratory illness of a virus related to chimpanzee coryza agent (CCA). II. Epidemiologic aspects of infection in infants and young children. Am. J. Hyg. 66, 291-300 (1957)

4. Glezen, W. P., Taber, L. H., Frank, A. L. \& Kasel, J. A Risk of primary infection and reinfection with respiratory syncytial virus. Am. J. Dis. Child 140, 543-546 (1986).

5. Shi, T. et al. Global, regional, and national disease burden estimates of acute lower respiratory infections due to respiratory syncytial virus in young children in 2015: a systematic review and modelling study. Lancet 390, 946-958 (2017).

6. Falsey, A. R., Hennessey, P. A., Formica, M. A., Cox, C. \& Walsh, E. E. Respiratory syncytial virus infection in elderly and high-risk adults. N. Engl. J. Med. 352 1749-1759 (2005).

7. van den Hoogen, B. G. et al. A newly discovered human pneumovirus isolated from young children with respiratory tract disease. Nat. Med. 7, 719-724 (2001).

This work describes the first isolation of human metapneumovirus from children.

8. Panda, S., Mohakud, N. K., Pena, L. \& Kumar, S. Human metapneumovirus: review of an important respiratory pathogen. Int. J. Infect. Dis. 25, 45-52 (2014).

9. Hall, C. B. Respiratory syncytial virus: its transmission in the hospital environment. Yale J. Biol. Med. $\mathbf{5 5}$ 219-223 (1982)

10. Haas, L. E., Thijsen, S. F., van Elden, L. \& Heemstra, K. A Human metapneumovirus in adults. Viruses 5, 87-110 (2013).

11. Grayson, S. A., Griffiths, P. S., Perez, M. K. $\&$ Piedimonte, G. Detection of airborne respiratory syncytial virus in a pediatric acute care clinic. Pediatr. Pulmonol. 52, 684-688 (2017).

12. Collins, P. L. \& Graham, B. S. Viral and host factors in human respiratory syncytial virus pathogenesis. J. Virol. 82, 2040-2055 (2008)

13. Peebles, R. S. Jr \& Graham, B. S. Pathogenesis of respiratory syncytial virus infection in the murine model. Proc. Am. Thorac Soc. 2, 110-115 (2005).

14. Kim, H. W. et al. Respiratory syncytial virus disease in infants despite prior administration of antigenic inactivated vaccine. Am. J. Epidemiol. 89, 422-434 (1969).

15. Kapikian, A. Z Mitchell, R. H., Chanock, R. M. Shvedoff, R. A. \& Stewart, C. E. An epidemiologic study of altered clinical reactivity to respiratory syncytial (RS) virus infection in children previously vaccinated with an inactivated RS virus vaccine. Am. J. Epidemiol. 89, 405-421 (1969).

16. Fulginiti, V. A. et al. Respiratory virus immunization. I. A field trial of two inactivated respiratory virus vaccines; an aqueous trivalent parainfluenza virus vaccine and an alum-precipitated respiratory syncytia virus vaccine. Am. J. Epidemiol. 89, 435-448 (1969).

17. Chin, J., Magoffin, R. L., Shearer, L. A., Schieble, J. H. \& Lennette, E. H. Field evaluation of a respiratory syncytial virus vaccine and a trivalent parainfluenza virus vaccine in a pediatric population. $\mathrm{Am}$. J. Epidemiol. 89, 449-463 (1969).

18. Prince, G. A., Curtis, S. J., Yim, K. C. \& Porter, D. D. Vaccine-enhanced respiratory syncytial virus disease in cotton rats following immunization with Lot 100 or a newly prepared reference vaccine. J. Gen. Virol. 82, 2881-2888 (2001). 
19. Polack, F. P. et al. A role for immune complexes in enhanced respiratory syncytial virus disease. J. Exp. Med. 196, 859-865 (2002) This manuscript demonstrates that vaccine enhanced disease is mediated by immune complexes.

20. Homaira, N., Rawlinson, W., Snelling, T. L. \& Jaffe, A Effectiveness of palivizumab in preventing RSV hospitalization in high risk children: a real-world perspective. Int. J. Pediatr. 2014, 571609 (2014)

21. Fearns, R. \& Collins, P. L. Role of the M2-1 transcription antitermination protein of respiratory syncytial virus in sequential transcription. J. Virol. 73, 5852-5864 (1999).

22. Collins, P. L., Hill, M. G., Cristina, J. \& Grosfeld, H. Transcription elongation factor of respiratory syncytial virus, a nonsegmented negative-strand RNA virus. Proc. Natl Acad. Sci. USA 93, 81-85 (1996).

23. Bermingham, A. \& Collins, P. L. The M2-2 protein of human respiratory syncytial virus is a regulatory factor involved in the balance between RNA replication and transcription. Proc Natl Acad Sci. USA 96, 11259-11264 (1999)

24. Bitko, V. et al. Nonstructural proteins of respiratory syncytial virus suppress premature apoptosis by an NF-кB-dependent, interferon-independent mechanism and facilitate virus growth. J. Virol. 81, 1786-1795 (2007).

25. Spann, K. M., Tran, K. C. \& Collins, P. L. Effects of nonstructural proteins NS1 and NS2 of human respiratory syncytial virus on interferon regulatory factor 3, NF-kB, and proinflammatory cytokines. J. Virol. 79, 5353-5362 (2005).

26. Gan, S. W. et al. The small hydrophobic protein of the human respiratory syncytial virus forms pentameric ion channels. J. Biol. Chem. 287, 24671-24689 (2012)

27. Fuentes, S., Tran, K. C., Luthra, P., Teng, M. N $\& \mathrm{He}, \mathrm{B}$. Function of the respiratory syncytial virus small hydrophobic protein. J. Virol. 81, 8361-8366 (2007).

28. Baviskar P. S., Hotard A L., Moore M. L. $\&$ Oomens, A. G. The respiratory syncytial virus fusion protein targets to the perimeter of inclusion bodies and facilitates filament formation by a cytoplasmic tail-dependent mechanism. J. Virol. 87 10730-10741 (2013)

29. Shaikh, F. Y. et al. A critical phenylalanine residue in the respiratory syncytial virus fusion protein cytoplasmic tail mediates assembly of internal viral proteins into viral filaments and particles. mBio 3, e00270-1 (2012).

30. Oomens, A. G., Bevis, K. P. \& Wertz, G. W. The cytoplasmic tail of the human respiratory syncytial virus $\mathrm{F}$ protein plays critical roles in cellular localization of the $\mathrm{F}$ protein and infectious progeny production. J. Virol. 80, 10465-10477 (2006).

31. Marty, A., Meanger, J., Mills, J., Shields, B. $\&$ Ghildyal, R. Association of matrix protein of respiratory syncytial virus with the host cell membrane of infected cells. Arch. Virol. 149, 199-210 (2004).

32. Kiss, G. et al. Structural analysis of respiratory syncytial virus reveals the position of M2-1 between the matrix protein and the ribonucleoprotein complex. J. Virol. 88, 7602-7617 (2014).

33. Tawar, R. G. et al. Crystal structure of a nucleocapsid-like nucleoprotein-RNA complex of respiratory syncytial virus. Science 326, 1279-1283 (2009).

34. Rixon, H. W. et al. The small hydrophobic (SH) protein accumulates within lipid-raft structures of the Golgi complex during respiratory syncytial virus infection. J. Gen. Virol. 85, 1153-1165 (2004)

35. Bukreyev, A., Whitehead, S. S., Murphy, B. R. $\&$ Collins, P. L. Recombinant respiratory syncytial virus from which the entire $\mathrm{SH}$ gene has been deleted grows efficiently in cell culture and exhibits site-specific attenuation in the respiratory tract of the mouse. J. Virol. 71, 8973-8982 (1997).

36. Levine, S., Klaiber-Franco, R. \& Paradiso, P. R. Demonstration that glycoprotein $\mathrm{G}$ is the attachment protein of respiratory syncytial virus. J. Gen. Virol. 68 2521-2524 (1987)

37. Hendricks, D. A., Baradaran, K., McIntosh, K. $\&$ Patterson, J. L. Appearance of a soluble form of the $G$ protein of respiratory syncytial virus in fluids of infected cells. J. Gen. Virol. 68, 1705-1714 (1987).

38. Wertz, G. W. et al. Nucleotide sequence of the $G$ protein gene of human respiratory syncytial virus reveals an unusual type of viral membrane protein. Proc. Natl Acad. Sci. USA 82, 4075-4079 (1985).
39. Collins, P. L. \& Mottet, G. Oligomerization and post-translational processing of glycoprotein $\mathrm{G}$ of human respiratory syncytial virus: altered O-glycosylation in the presence of brefeldin A. J. Gen. Virol. 73, 849-863 (1992).

40. Satake, M., Coligan, J. E., Elango, N., Norrby, E. $\&$ Venkatesan, S. Respiratory syncytial virus envelope glycoprotein (G) has a novel structure. Nucleic Acids Res. 13, 7795-7812 (1985)

41. Garcia-Beato, R. et al. Host cell effect upon glycosylation and antigenicity of human respiratory syncytial virus G glycoprotein. Virology 221, 301-309 (1996).

42. Kwilas, S. et al. Respiratory syncytial virus grown in Vero cells contains a truncated attachment protein that alters its infectivity and dependence on glycosaminoglycans. J. Virol. 83, 10710-10718 (2009)

43. Roberts, S. R., Lichtenstein, D., Ball, L. A. \& Wertz, G. W. The membrane-associated and secreted forms of the respiratory syncytial virus attachment glycoprotein $\mathrm{G}$ are synthesized from alternative initiation codons. J. Virol. 68, 4538-4546 (1994).

44. Hendricks, D. A., Mclntosh, K. \& Patterson, J. L. Further characterization of the soluble form of the $G$ glycoprotein of respiratory syncytial virus. J. Virol. 62 2228-2233 (1988).

45. Bukreyev, A Yang L \& Collins, P L. The secreted C protein of human respiratory syncytial virus antagonizes antibody-mediated restriction of replication involving macrophages and complement. J. Virol. 86, 10880-10884 (2012).

46. Bukreyev, A. et al. The secreted form of respiratory syncytial virus $G$ glycoprotein helps the virus evade antibody-mediated restriction of replication by acting as an antigen decoy and through effects on $\mathrm{Fc}$ receptor-bearing leukocytes. J. Virol. 82 12191-12204 (2008)

47. Gorman, J. J., Ferguson, B. L., Speelman, D. \& Mills, J. Determination of the disulfide bond arrangement of human respiratory syncytial virus attachment (G) protein by matrix-assisted laser desorption/ionization time-of-flight mass spectrometry. Protein Sci. 6 1308-1315 (1997).

48. Langedijk, J. P., Schaaper, W. M., Meloen, R. H. $\varnothing$ van Oirschot, J. T. Proposed three-dimensional model for the attachment protein $\mathrm{G}$ of respiratory syncytial virus. J. Gen. Virol 77, 1249-1257 (1996).

49. Doreleijers, J. F et al. Solution structure of the immunodominant region of protein $\mathrm{G}$ of bovine respiratory syncytial virus. Biochemistry 35 , 14684-14688 (1996).

This study determines the first 3D structure of the RSV G cystine noose.

50. Sugawara, M. et al. Structure-antigenicity relationship studies of the central conserved region of human respiratory syncytial virus protein G. J. Pept. Res. 60 , 271-282 (2002)

51. Langedijk, J. P., de Groot, B. L., Berendsen, H. J. $\&$ van Oirschot, J. T. Structural homology of the central conserved region of the attachment protein $\mathrm{G}$ of respiratory syncytial virus with the fourth subdomain of 55-kDa tumor necrosis factor receptor. Virology 243, 293-302 (1998)

52. Jones, H. G. et al. Structural basis for recognition of the central conserved region of RSV G by neutralizing human antibodies. PLOS Pathog. 14, e1006935 (2018).

53. Fedechkin, S. O., George, N. L., Wolff, J. T., Kauvar, L. M. $\Sigma$ DuBois, R. M. Structures of respiratory syncytial virus $\mathrm{G}$ antigen bound to broadly neutralizing antibodies. Sci. Immunol. 3, eaar3534 (2018).

54. Pangesti, K. N. A. Abd El Ghany, M., Walsh, M. G. Kesson, A. M. \& Hill-Cawthorne, G. A. Molecular epidemiology of respiratory syncytial virus. Rev. Med. Virol. 28, e 1968 (2018)

55. Mufson, M. A., Orvell, C., Rafnar, B. \& Norrby, E. Two distinct subtypes of human respiratory syncytial virus. J. Gen. Virol. 66, 2111-2124 (1985).

56. Anderson, L. J. et al. Antigenic characterization of respiratory syncytial virus strains with monoclonal antibodies. J. Infect. Dis. 151, 626-633 (1985).

57. Hall, C. B et al. Occurrence of groups A and B of respiratory syncytial virus over 15 years: associated epidemiologic and clinical characteristics in hospitalized and ambulatory children. J. Infect. Dis. 162, 1283-1290 (1990)

58. Trento, A. et al. Major changes in the $G$ protein of human respiratory syncytial virus isolates introduced by a duplication of 60 nucleotides. J. Gen. Virol. $\mathbf{8 4}$, 3115-3120 (2003)

59. Trento, A. et al. Natural history of human respiratory syncytial virus inferred from phylogenetic analysis of the attachment $(G)$ glycoprotein with a 60-nucleotide duplication J. Virol 80, 975-984 (2006).

60. Trento, A. et al. Ten years of global evolution of the human respiratory syncytial virus BA genotype with a 60 -nucleotide duplication in the $\mathrm{G}$ protein gene. J. Virol. 84, 7500-7512 (2010).

61. Eshaghi, A. et al. Genetic variability of human respiratory syncytial virus $A$ strains circulating in Ontario: a novel genotype with a 72 nucleotide $G$ gene duplication. PLOS ONE 7, e32807 (2012).

62. Duvvuri, V. R. et al. Genetic diversity and evolutionary insights of respiratory syncytial virus A ON 1 genotype: global and local transmission dynamics. Sci. Rep. 5, 14268 (2015)

63. Hirano, E. et al. Molecular evolution of human respiratory syncytial virus attachment glycoprotein $(G)$ gene of new genotype ON1 and ancestor NA1. Infect. Genet. Evol. 28, 183-191 (2014).

64. Hotard, A. L., Laikhter, E., Brooks, K., Hartert, T. V. $\&$ Moore, M. L. Functional analysis of the 60 -nucleotide duplication in the respiratory syncytial virus buenos aires strain attachment glycoprotein. J. Virol. 89 8258-8266 (2015).

65. Leyrat, C., Paesen, G. C., Charleston, J., Renner, M $\&$ Grimes, J. M. Structural insights into the human metapneumovirus glycoprotein ectodomain. J. Virol. 88, 11611-11616 (2014)

66. Yin, H. S., Wen, X., Paterson, R. G., Lamb, R. A $\&$ Jardetzky, T. S. Structure of the parainfluenza virus $5 \mathrm{~F}$ protein in its metastable, prefusion conformation. Nature 439, 38-44 (2006).

67. Yin, H. S., Paterson, R. G., Wen, X., Lamb, R. A $\&$ Jardetzky, T. S. Structure of the uncleaved ectodomain of the paramyxovirus (hPIV3) fusion protein. Proc. Natl Acad. Sci. USA 102, 9288-9293 (2005).

68. Collins, P. L., Huang Y. T \& Wertz, G. W. Nucleotide sequence of the gene encoding the fusion $(F)$ glycoprotein of human respiratory syncytial virus. Proc. Natl Acad. Sci. USA 81, 7683-7687 (1984).

69. Zimmer, G., Budz, L. \& Herrler, G. Proteolytic activation of respiratory syncytial virus fusion protein. Cleavage at two furin consensus sequences. J. Biol. Chem. 276, 31642-31650 (2001)

70. Gonzalez-Reyes, L. et al. Cleavage of the human respiratory syncytial virus fusion protein at two distinct sites is required for activation of membrane fusion. Proc. Natl Acad. Sci. USA 98, 9859-9864 (2001).

71. Bolt, G., Pedersen, L. O. \& Birkeslund, H. H. Cleavage of the respiratory syncytial virus fusion protein is required for its surface expression: role of furin Virus Res. 68, 25-33 (2000).

72. Collins, P. L. $\&$ Mottet, G. Post-translational processing and oligomerization of the fusion glycoprotein of human respiratory syncytial virus. J. Gen. Virol. 72 , 3095-3101 (1991).

73. Day, N. D. et al. Contribution of cysteine residues in the extracellular domain of the F protein of human respiratory syncytial virus to its function. Virol. J. 3 34 (2006)

74. Gilman, M. S et al. Characterization of a prefusionspecific antibody that recognizes a quaternary, cleavage-dependent epitope on the RSV fusion glycoprotein. PLOS Pathog. 11, e 1005035 (2015)

75. Krarup, A. et al. A highly stable prefusion RSV F vaccine derived from structural analysis of the fusion mechanism. Nat. Commun. 6, 8143 (2015).

76. McLellan, J. S. et al. Structure of RSV fusion glycoprotein trimer bound to a prefusion-specific neutralizing antibody. Science 340, 1113-1117 (2013).

This work provides the first 3D structure of the prefusion conformation of RSV F and defines a major antigenic site recognized by prefusion-specific antibodies

77. Liljeroos, L., Krzyzaniak, M. A., Helenius, A. $\&$ Butcher, S. J. Architecture of respiratory syncytial virus revealed by electron cryotomography. Proc. Natl Acad. Sci. USA 110, 11133-11138 (2013). This manuscript reveals the organization and morphology of RSV virions by cryo-electron tomography.

78. Killikelly, A. M., Kanekiyo, M. \& Graham, B. S. Pre-fusion $F$ is absent on the surface of formalin-inactivated respiratory syncytial virus. Sci. Rep. 6, 34108 (2016).

79. Kim, Y. H. et al. Capture and imaging of a prehairpin fusion intermediate of the paramyxovirus PIV5 Proc. Natl Acad. Sci. USA 108, 20992-20997 (2011).

80. Zhao, X., Singh, M., Malashkevich, V. N. \& Kim, P. S Structural characterization of the human respiratory 
syncytial virus fusion protein core. Proc. Natl Acad. Sci. USA 97, 14172-14177 (2000).

81. McLellan, J. S., Yang, Y., Graham, B. S. \& Kwong, P. D. Structure of respiratory syncytial virus fusion glycoprotein in the postfusion conformation reveals preservation of neutralizing epitopes. J. Virol. 85 7788-7796 (2011).

82. Swanson, K. A. et al. Structural basis for immunization with postfusion respiratory syncytial virus fusion $F$ glycoprotein (RSV F) to elicit high neutralizing antibody titers. Proc. Natl Acad. Sci. USA 108 9619-9624 (2011).

83. Johnson, J. E., Gonzales, R. A., Olson, S. J., Wright, P. F \& Graham, B. S. The histopathology of fatal untreated human respiratory syncytial virus infection. Mod. Pathol. 20, 108-119 (2007).

84. $\mathrm{Xu}$, L. et al. A fatal case associated with respiratory syncytial virus infection in a young child. BMC Infect. Dis. 18, 217 (2018)

85. Pitkaranta, A., Virolainen, A., Jero, J., Arruda, E. $\&$ Hayden, F. G. Detection of rhinovirus, respiratory syncytial virus, and coronavirus infections in acute otitis media by reverse transcriptase polymerase chain reaction. Pediatrics 102, 291-295 (1998).

86. Rohwedder, A. et al. Detection of respiratory syncytial virus RNA in blood of neonates by polymerase chain reaction. J. Med. Virol. 54, 320-327 (1998)

87. Escribano-Romero, E., Rawling, J., Garcia-Barreno, B. $\&$ Melero, J. A. The soluble form of human respiratory syncytial virus attachment protein differs from the membrane-bound form in its oligomeric state but is still capable of binding to cell surface proteoglycans. J. Virol. 78, 3524-3532 (2004)

88. Krusat, T. $\&$ Streckert, H. J. Heparin-dependent attachment of respiratory syncytial virus (RSV) to host cells. Arch. Virol 142, 1247-1254 (1997).

89. Feldman, S. A., Hendry, R. M. \& Beeler, J. A. Identification of a linear heparin binding domain for human respiratory syncytial virus attachment glycoprotein G. J. Virol. 73, 6610-6617 (1999).

90. Hallak, L. K., Spillmann, D., Collins, P. L. \& Peeples, M. E. Glycosaminoglycan sulfation requirements for respiratory syncytial virus infection. J. Virol. 74, 10508-10513 (2000)

91. Martinez, I. \& Melero, J. A. Binding of human respiratory syncytial virus to cells: implication of sulfated cell surface proteoglycans. J. Gen. Virol. $\mathbf{8 1}$ 2715-2722 (2000)

92. Hallak, L. K., Collins, P. L., Knudson, W. ¿ Peeples, M. E. Iduronic acid-containing glycosaminoglycans on target cells are required for efficient respiratory syncytial virus infection. Virology 271, 264-275 (2000)

93. Chirkova, T. et al. CX3CR1 is an important surface molecule for respiratory syncytial virus infection in human airway epithelial cells. J. Gen. Virol. 96 2543-2556 (2015)

94. Zhang, L. et al. Infection of ciliated cells by human parainfluenza virus type 3 in an in vitro model of human airway epithelium. J. Virol. 79, 1113-1124 (2005).

95. Zhang, L., Peeples, M. E., Boucher, R. C., Collins, P. L. $\&$ Pickles, R. J. Respiratory syncytial virus infection of human airway epithelial cells is polarized, specific to ciliated cells, and without obvious cytopathology. J. Virol. 76, 5654-5666 (2002).

96. Johnson, S. M. et al. Respiratory syncytial virus uses CX3CR 1 as a receptor on primary human airway epithelial cultures. PLOS Pathog. 11, e1005318 (2015).

97. Tripp, R. A. et al. CX3C chemokine mimicry by respiratory syncytial virus $G$ glycoprotein Nat. Immunol. 2, 732-738 (2001) This study identifies the $\mathrm{CX}_{3} \mathrm{C}$ motif in RSV G and demonstrates that $\mathrm{CX}_{3} \mathrm{CR} 1$ facilitates RSV entry.

98. Bazan, J. F. et al. A new class of membrane-bound chemokine with a CX3C motif. Nature 385, 640-644 (1997).

99. Jeong, K. I. et al. CX3CR 1 is expressed in differentiated human ciliated airway cells and co-localizes with respiratory syncytial virus on cilia in a $\mathrm{G}$ protein dependent manner. PLOS ONE 10, e0130517 (2015).

100. Karron, R. A. et al. Respiratory syncytial virus (RSV) $\mathrm{SH}$ and $\mathrm{G}$ proteins are not essential for vira replication in vitro: clinical evaluation and molecular characterization of a cold-passaged, attenuated RSV subgroup B mutant. Proc. Natl Acad. Sci. USA 94, 13961-13966 (1997).

This work demonstrates that infectious RSV requires only the $F$ protein on its surface.

101. Techaarpornkul, S., Barretto, N. \& Peeples, M. E. Functional analysis of recombinant respiratory syncytial virus deletion mutants lacking the small hydrophobic and/or attachment glycoprotein gene. J. Virol. 75, 6825-6834 (2001)

102. Feldman, S. A., Audet, S. \& Beeler, J. A. The fusion glycoprotein of human respiratory syncytial virus facilitates virus attachment and infectivity via an interaction with cellular heparan sulfate. J. Virol. 74 6442-6447 (2000).

103. Behera, A. K. et al. Blocking intercellular adhesion molecule- 1 on human epithelial cells decreases respiratory syncytial virus infection. Biochem. Biophys. Res. Commun. 280, 188-195 (2001).

104. Currier, M. G. et al. EGFR interacts with the fusion protein of respiratory syncytial virus strain 2-20 and mediates infection and mucin expression. PLOS Pathog. 12, e1005622 (2016).

105. Tayyari, F. et al. Identification of nucleolin as a cellular receptor for human respiratory syncytial virus. Nat. Med. 17, 1132-1135 (2011). This manuscript identifies nucleolin as a host cel factor that interacts with the $F$ protein and facilitates RSV entry.

106. Bose, S., Basu, M. \& Banerjee, A. K. Role of nucleolin in human parainfluenza virus type 3 infection of human lung epithelial cells. J. Virol. 78, 8146-8158 (2004).

107. Su, P. Y. et al. Cell surface nucleolin facilitates enterovirus 71 binding and infection. J. Virol. 89, 4527-4538 (2015).

108. Xiao, X., Feng, Y., Zhu, Z. \& Dimitrov, D. S. Identification of a putative Crimean-Congo hemorrhagic fever virus entry factor. Biochem. Biophys. Res. Commun. 411, 253-258 (2011)

109. Qiu, J. \& Brown, K. E. A. 110-kDa nuclear shuttle protein, nucleolin, specifically binds to adeno-associated virus type 2 (AAV-2) capsid. Virology 257, 373-382 (1999).

110. Callebaut, C. et al. Identification of V3 loop-binding proteins as potential receptors implicated in the binding of HIV particles to CD4 ${ }^{+}$cells. J. Biol. Chem 273, 21988-21997 (1998).

111. Srinivasakumar, N., Ogra, P. L. \& Flanagan, T. D. Characteristics of fusion of respiratory syncytial virus with HEp-2 cells as measured by R 18 fluorescence dequenching assay. J. Virol. 65, 4063-4069 (1991).

112. Kahn, J. S., Schnell, M. J., Buonocore, L. \& Rose, J. K. Recombinant vesicular stomatitis virus expressing respiratory syncytial virus (RSV) glycoproteins: RSV fusion protein can mediate infection and cell fusion. Virology 254, 81-91 (1999).

113. White, J. M. \& Whittaker, G. R. Fusion of enveloped viruses in endosomes. Traffic 17, 593-614 (2016).

114. San-Juan-Vergara, H. et al. Cholesterol-rich microdomains as docking platforms for respiratory syncytial virus in normal human bronchial epithelial cells. J. Virol. 86, 1832-1843 (2012).

115. Krzyzaniak, M. A Zumstein, M. T., Gerez, J. A Picotti, P. \& Helenius, A. Host cell entry of respiratory syncytial virus involves macropinocytosis followed by proteolytic activation of the F protein. PLOS Pathog. 9, e1003309 (2013)

116. Schlender, J., Zimmer, G., Herrler, G. \& Conzelmann, K. K. Respiratory syncytial virus (RSV) fusion protein subunit F2, not attachment protein $G$ determines the specificity of RSV infection. J. Virol. 77, 4609-4616 (2003).

117. Yuan, P. et al. Structural studies of the parainfluenza virus 5 hemagglutinin-neuraminidase tetramer in complex with its receptor, sialyllactose. Structure 13, 803-815 (2005)

118. Crennell, S., Takimoto, T., Portner, A. \& Taylor, G. Crystal structure of the multifunctional paramyxovirus hemagglutinin-neuraminidase. Nat. Struct. Biol. 7 , 1068-1074 (2000)

119. Bose, S., Jardetzky, T. S. \& Lamb, R. A. Timing is everything: fine-tuned molecular machines orchestrate paramyxovirus entry. Virology 479-480, 518-531 (2015).

120. Yunus, A. S. et al. Elevated temperature triggers human respiratory syncytial virus $F$ protein six-helix bundle formation. Virology 396, 226-237 (2010).

121. Fearns, R. \& Deval, J. New antiviral approaches for respiratory syncytial virus and other mononegaviruses: inhibiting the RNA polymerase. Antiviral Res. 134, 63-76 (2016)

122. Falsey, A. R. \& Walsh, E. E. Relationship of serum antibody to risk of respiratory syncytial virus infection in elderly adults. J. Infect. Dis. 177, 463-466 (1998).

123. Hall, C. B., Walsh, E. E., Long, C. E. \& Schnabel, K. C. Immunity to and frequency of reinfection with respiratory syncytial virus. J. Infect. Dis. 163 693-698 (1991)
124. American Academy of Pediatrics. Respiratory syncytial virus immune globulin intravenous: indications for use. Committee on Infectious Diseases, Committee on Fetus and Newborn. Pediatrics 99, 645-650 (1997)

125. The IMpact-RSV Study Group. Palivizumab, a humanized respiratory syncytial virus monoclonal antibody, reduces hospitalization from respiratory syncytial virus infection in high-risk infants. Pediatrics 102, 531-537 (1998)

126. Beeler, J. A. \& Coelingh, K. V. Neutralization epitopes of the F-glycoprotein of respiratory syncytial virus effect of mutation upon fusion function. J. Virol. 63 2941-2950 (1989).

127. Kwakkenbos, M. J. et al. Generation of stable monoclonal antibody-producing B cell receptor-positive human memory $B$ cells by genetic programming. Nat. Med. 16, 123-128 (2010). This study reports the isolation and characterization of the first prefusion F-specific monoclonal antibodies, although their specificity was not known at the time.

128. Goodwin, E. et al. Infants infected with respiratory syncytial virus generate potent neutralizing antibodies that lack somatic hypermutation. Immunity $\mathbf{4 8}$ 339-349 (2018).

129. Gilman, M. S. et al. Rapid profiling of RSV antibody repertoires from the memory B cells of naturally infected adult donors. Sci. Immunol. 1 (2016).

130. Collarini, E. J. et al. Potent high-affinity antibodies for treatment and prophylaxis of respiratory syncytial virus derived from $B$ cells of infected patients. J. Immunol. 183, 6338-6345 (2009).

131. Mousa, J. J., Kose, N., Matta, P., Gilchuk, P. $\&$ Crowe, J. E. Jr. A novel pre-fusion conformationspecific neutralizing epitope on the respiratory syncytial virus fusion protein. Nat Microbiol. 2, 16271 (2017).

132. Corti, D et al. Cross-neutralization of four paramyxoviruses by a human monoclonal antibody. Nature 501, 439-443 (2013).

133. Zhu, Q. et al. A highly potent extended half-life antibody as a potential RSV vaccine surrogate for all infants. Sci. Transl Med. 9, eaaj1928 (2017).

134. US National Library of Medicine. ClinicalTrials.gov https://clinicaltrials.gov/ct2/show/NCT02878330 (2018).

135. US National Library of Medicine. ClinicalTrials.gov https://clinicaltrials.gov/ct2/show/NCT02325791 (2018)

136. Costello, H. M., Ray, W. C., Chaiwatpongsakorn, S. \& Peeples, M. E. Targeting RSV with vaccines and small molecule drugs. Infect. Disord. Drug Targets 12 110-128 (2012).

137. Heylen, E., Neyts, J. \& Jochmans, D. Drug candidates and model systems in respiratory syncytial virus antiviral drug discovery. Biochem. Pharmacol. 127 $1-12$ (2017).

138. Cianci, C et al. Targeting a binding pocket within the trimer-of-hairpins: small-molecule inhibition of viral fusion. Proc. Natl Acad. Sci. USA 101, 15046-15051 (2004).

139. Roymans, D. et al. Binding of a potent small-molecule inhibitor of six-helix bundle formation requires interactions with both heptad-repeats of the RSV fusion protein. Proc. Natl Acad. Sci. USA 107, 308-313 (2010)

140. Yan, D. et al. Cross-resistance mechanism of respiratory syncytial virus against structurally diverse entry inhibitors. Proc. Natl Acad. Sci. USA 111 E3441-E3449 (2014).

141. Battles, M. B. et al. Molecular mechanism of respiratory syncytial virus fusion inhibitors. Nat. Chem Biol. 12, 87-93 (2016)

This work describes the binding site and mechanism of action for small-molecule fusion inhibitors.

142. Samuel, D. et al. GS-5806 inhibits pre- to postfusion conformational changes of the respiratory syncytial virus fusion protein. Antimicrob. Agents Chemother. 59, 7109-7112 (2015)

143. DeVincenzo, J. P. et al. Oral GS-5806 activity in a respiratory syncytial virus challenge study. $N$. Engl. J. Med. 371, 711-722 (2014).

144. Stevens, M et al Antiviral activity of oral JNJ53718678 in healthy adult volunteers challenged with respiratory syncytial virus: a placebo-controlled study. J. Infect. Dis. 218, 748-756 (2018).

145. Mazur, N. I. et al. The respiratory syncytial virus vaccine landscape: lessons from the graveyard and promising candidates. Lancet Infect. Dis. 18, e295-e311 (2018)

146. Graham, B. S. Vaccine development for respiratory syncytial virus. Curr. Opin. Virol. 23, 107-112 (2017). 
147. Magro, M. et al. Neutralizing antibodies against the preactive form of respiratory syncytial virus fusion protein offer unique possibilities for clinical intervention. Proc. Natl Acad. Sci. USA 109, 3089-3094 (2012). This study provides the first evidence for the existence of prefusion F-specific antibodies and their dominant contribution to the RSV-neutralizing activity of human sera.

148. Ngwuta, J. O. et al. Prefusion F-specific antibodies determine the magnitude of RSV neutralizing activity in human sera. Sci. Transl Med. 7, 309ra162 (2015).

149. McLellan, J. S. et al. Structure-based design of a fusion glycoprotein vaccine for respiratory syncytial virus. Science 342, 592-598 (2013). This manuscript reports the first structure-based design of a prefusion $F$ vaccine antigen and demonstrates its superior immunogenicity to postfusion $\mathrm{F}$ antigens.

150. US National Library of Medicine. ClinicalTrials.gov https://clinicaltrials.gov/ct2/show/NCT03049488 (2018).

151. US National Library of Medicine. ClinicalTrials.gov https://clinicaltrials.gov/ct2/show/NCT03529773 (2018).

152. Falloon, J. et al. An adjuvanted, postfusion $F$ protein-based vaccine did not prevent respiratory syncytial virus illness in older adults. J. Infect. Dis. 216, 1362-1370 (2017).

153. US National Library of Medicine. ClinicalTrials.gov https://clinicaltrials. gov/ct2/show/NCT02608502 (2017).

154. US National Library of Medicine. ClinicalTrials.gov https://clinicaltrials.gov/ct2/show/NCT02508194 (2017).

155. US National Library of Medicine. ClinicalTrials.gov https://clinicaltrials.gov/ct2/show/NCT02624947 (2018).

156. Karron, R. A., Buchholz, U. J. \& Collins, P. L. Live-attenuated respiratory syncytial virus vaccines. Curr. Top. Microbiol. Immunol. 372, 259-284 (2013).

157. Karron, R. A. et al. A gene deletion that up-regulates viral gene expression yields an attenuated RSV vaccine with improved antibody responses in children. Sci. Transl Med. 7, 312 ra175 (2015).

158. Liang, B. et al. Improved prefusion stability, optimized codon usage, and augmented virion packaging enhance the immunogenicity of respiratory syncytial virus fusion protein in a vectored-vaccine candidate. J. Virol. 91, e00189-17 (2017).

159. Stobart, C. C. et al. A live RSV vaccine with engineered thermostability is immunogenic in cotton rats despite high attenuation. Nat. Commun. 7 13916 (2016).

160. US National Library of Medicine. ClinicalTrials.gov https://clinicaltrials.gov/ct2/show/NCT03303625 (2018).
161. US National Library of Medicine. ClinicalTrials.gov https:/clinicaltrials.gov/ct2/show/NCT02927873 (2018).

162. US National Library of Medicine. ClinicalTrials.gov https://clinicaltrials.gov/ct2/show/NCT02873286 (2018).

163. Levine, S. Polypeptides of respiratory syncytial virus. J. Virol. 21, 427-431 (1977).

164. Walsh, E. E. \& Hruska, J. Monoclonal antibodies to respiratory syncytial virus proteins: identification of the fusion protein. J. Virol. 47, 171-177 (1983).

165. Garcia, J., Garcia-Barreno, B., Vivo, A. \& Melero, J. A Cytoplasmic inclusions of respiratory syncytial virus-infected cells: formation of inclusion bodies in transfected cells that coexpress the nucleoprotein, the phosphoprotein, and the $22 \mathrm{~K}$ protein. Virology 195 , 243-247 (1993)

166. Garcia-Barreno, B., Delgado, T. \& Melero, J. A. Identification of protein regions involved in the interaction of human respiratory syncytial virus phosphoprotein and nucleoprotein: significance for nucleocapsid assembly and formation of cytoplasmic inclusions. J. Virol. 70, 801-808 (1996).

167. Rincheval, V. et al. Functional organization of cytoplasmic inclusion bodies in cells infected by respiratory syncytial virus. Nat. Commun. 8, 563 (2017).

168. Noton, S. L. \& Fearns, R. Initiation and regulation of paramyxovirus transcription and replication. Virology 479-480, 545-554 (2015)

169. Gower, T. L. et al. RhoA signaling is required for respiratory syncytial virus-induced syncytium formation and filamentous virion morphology. J. Virol. 79, 5326-5336 (2005)

170. Ke, Z. et al. The morphology and assembly of respiratory syncytial virus revealed by cryo-electron tomography. Viruses 10, E446 (2018).

This work conclusively demonstrates that RSV is a filamentous virus upon budding from infected cells

171. Mehedi, M. et al. Actin-related protein 2 (ARP2) and virus-induced filopodia facilitate human respiratory syncytial virus spread. PLOS Pathog. 12, e 1006062 (2016).

172. Vanover, D. et al. RSV glycoprotein and genomic RNA dynamics reveal filament assembly prior to the plasma membrane. Nat. Commun. 8, 667 (2017).

173. Forster, A., Maertens, G. N., Farrell, P. J. \& Bajorek, M. Dimerization of matrix protein is required for budding of respiratory syncytial virus. J. Virol. 89, 4624-4635 (2015).

174. Roberts, S. R., Compans, R. W. \& Wertz, G. W. Respiratory syncytial virus matures at the apical surfaces of polarized epithelial cells. J. Virol. 69 2667-2673 (1995).

175. Jardetzky, T. S. \& Lamb, R. A. Activation of paramyxovirus membrane fusion and virus entry. Curr. Opin. Virol. 5, 24-33 (2014).
176. Yuan, P. et al. Structure of the Newcastle disease virus hemagglutinin-neuraminidase $(\mathrm{HN})$ ectodomain reveals a four-helix bundle stalk. Proc. Natl Acad. Sci. USA 108, 14920-14925 (2011)

177. Welch, B. D. et al. Structure of the parainfluenza virus 5 (PIV5) hemagglutinin-neuraminidase (HN) ectodomain PLOS Pathog 9 e1003534 (2013).

178. Bose, S. et al. Fusion activation by a headless parainfluenza virus 5 hemagglutinin-neuraminidase stalk suggests a modular mechanism for triggering. Proc. Natl Acad. Sci. USA 109, E2625-E2634 (2012).

179. Brindley, M. A. et al. A stabilized headless measles virus attachment protein stalk efficiently triggers membrane fusion. J. Virol. 87, 11693-11703 (2013).

180. Liu, Q. et al. Unraveling a three-step spatiotemporal mechanism of triggering of receptor-induced Nipah virus fusion and cell entry. PLOS Pathog. 9, e1003770 (2013).

181. Iorio, R. M., Melanson, V. R. \& Mahon, P. J. Glycoprotein interactions in paramyxovirus fusion. Future Virol. 4, 335-351 (2009).

182. McLellan, J. S. Neutralizing epitopes on the respiratory syncytial virus fusion glycoprotein. Curr. Opin. Virol. 11, 70-75 (2015).

\section{Acknowledgements}

The authors dedicate this Review to the memory of José A Melero, a wonderful colleague and scientist who contributed much to the study of the RSV F and G proteins. The authors thank B. Graham, J. Langedijk and members of the McLellan laboratory for helpful comments on the manuscript, and M. Gilman for assistance with the figures.

\section{Author contributions}

M.B.B. researched data for the article M.B.B and J S.M. made substantial contributions to discussions of the content. M.B.B. and J.S.M. wrote the article. J.S.M. reviewed and edited the manuscript before submission.

\section{Competing interests}

J.S.M. is a named inventor on patents for vaccines and/or monoclonal antibodies for RSV and coronaviruses, has received research funding from Medlmmune and Janssen Pharmaceuticals, has been a paid consultant for Medlmmune and is on the scientific advisory board for Calder Biosciences. M.B.B. is currently employed by Adimab.

\section{Publisher's note}

Springer Nature remains neutral with regard to jurisdictional claims in published maps and institutional affiliations.

\section{Reviewer information}

Nature Reviews Microbiology thanks L. Bont and other anonymous reviewer(s) for their contribution to the peer review of this work. 